University of Rhode Island

DigitalCommons@URI

Open Access Master's Theses

1990

\title{
Assessment of Spiritual Development in College Students: A Qualitative Approach
}

Michael C. Cerullo

University of Rhode Island

Follow this and additional works at: https://digitalcommons.uri.edu/theses

\section{Recommended Citation}

Cerullo, Michael C., "Assessment of Spiritual Development in College Students: A Qualitative Approach" (1990). Open Access Master's Theses. Paper 1681.

https://digitalcommons.uri.edu/theses/1681

This Thesis is brought to you for free and open access by DigitalCommons@URI. It has been accepted for inclusion in Open Access Master's Theses by an authorized administrator of DigitalCommons@URI. For more information, please contact digitalcommons-group@uri.edu. 


\section{ASSESSMENT OF SPIRITUAL DEVELOPMENT \\ IN COLLEGE STUDENTS:}

A QUALITATIVE APPROACH

BY

MICHAEL C. CEERULLO

A THESIS SUBMITTED IN PARTIAL FULFILLMENT OF THE REQUIREMENTS FOR THE DEGREE OF MASTER OF SCIENCE

$\mathbf{I N}$

COLLEGE STUDENT PERSONNEL

THE UNIVERSITY OF RHODE ISLAND

1990

\# 22760107 


\section{Abstract}

This research pursues the design of a qualitative means of assessing Spiritual Awareness and Development in college students. An historical perspective regarding the relationship of religious, theological and spiritual concerns to higher education along with the projection of an emerging paradigm within which the student development profession can be expected to operate is presented. A review of the professional and related literature treating spiritual Development is given. A review of literature involving related aspects of Psychosocial, Cognitive, Ethical, Moral, Faith, Religious, Identity and Ego Development follows.

The significance of Life Story, Myth, Metaphor and Community to Spiritual Awareness and Development and other related Developmental models is discussed and a review of pertinent literature is presented. A Methodology incorporating these implications is then hypothesized. The first phase of a two phased pilot project to develop a qualitative assessment instrument is described and discussed.

In addition to establishing that the Process developed in Phase 1 can produce consistent and credible participant 'data' across several (5) small groups ( $\mathrm{n}=6-10)$, results suggest that the process can be applied as an Intervention and Curriculum component as well as a Research or Assessment Method. 


\section{Acknowledgement}

Connectedness, community and the feeling of belonging can be inspiring during a challenging and solitary journey. Indeed, while I've been writing this thesis they have been as cool spring water on a hot August day during a long climb to a White Mountain summit. There are many who have provided me these and other forms of nourishment during this time.

I am most indebted to my Major Professor, Dr.Jerome A Schaffran for helping me discover my interest in this research. He has been willing to share with me a view of the elegant 'glass bead game' he has been developing through the years. Without that privilege and the encouragement, patience and unselfish mentorship he has provided, I would not have been able to continue.

Dr J. Eugene Knott's tutelage in the area of small group interaction and the Myers-Briggs Type Indicator has been invaluable to helping me scope and 'fence in' this project.

The conversations I have had with Dr. George Willis have been most important to helping me locate a sense of style and technique on the continuum of Qualitative Research, Evaluation and Assessment.

Dr. Barbara Brittingham's critiques of my projects for her seminar in Special Topics in Higher Education provided an important impetus to my considering a commitment to a thesis project. 
Dr. Jayne Richmond's comprehensive courses in Principles \& Practices and Organization \& Administration in College Student Personnel have provided a dependable base from which to explore the future.

Research into Spirituality would not have been possible for me without connection to the communities in which it has been nurtured and shared. The Reverends John Hall and Donn Brown have been true friends and spiritual guides during this process.

The Reverend James Knudson, Mrs. Patricia Hallenbeck and Mrs. Nancy Willis, Mentors for The University of the South EFM Seminars in which I have participated over the years have long been supporting this project, some of the time without any of us knowing it. To them and my fellow EFM students I owe many thanks for the years of reflections and metaphor sharing .

Most importantly, there is my family. It is within this community that my experience of spirituality began.

My nine brothers and sisters, my grandparents, all my aunts and uncles, cousins, nieces and nephews have been regular and consistent reminders of my spiritual roots. My mother, Lillian, has always been a light and a support to my ventures.

Michael-Sean and Bryan, my sons and Erin, my daughter, have been and continue to be authentic friends and teachers. Throughout this project, my wife, Carden, has been a continuing source of encouragement and inspiration. 
Dedication

This work is dedicated to my Eather, Michael. Without having known him, I would not likely have begun to understand that Spirituality has meaning. 


\section{Preface}

There is a story about my father's parents which often circulates in the family of my mind.

Angelo is responding to Antoinetta's concern that his attention has become too focused on the symmetry of the beehive shaped foundry ovens he builds and on his tomato plants. She seems to be asking if something has changed between them after ten children and all these years.

He looks into her eyes, touches her hand and asks,

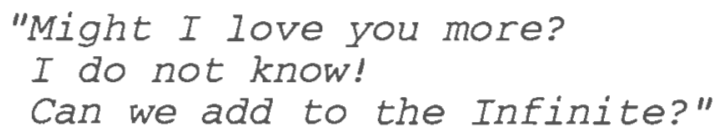

This and other images of my grandfather have been an important part of my life. They have been especially present to the experience of writing this thesis.

Orphaned before emigrating from the farmlands of Southern Italy, he arrived in Providence at 20, married Antoinetta and together they engaged the curriculum of the American Experience.

What I most remember is the way he sat on his porch. Quietly smoking his pipe and smiling, serene and in his place, my grandfather, at 70, was enjoying the fruits of a well and truly lived life. I have come to realize that, throughout it, he lived quite spiritually. 
Would he have called it spirituality? I cannot know that. Lately, though, I find myself in another of the family stories.

Grandpa Angelo is with his tomato plants.

I ask "Grandpa, How might I assess Spirituality?"

A cloud of parodi smoke drifts out from under his hat.

He has a tomato in each hand.

He gauges the weight of each.

"I wonder which is sweeter." he muses.

suddenly he is a young man of 20. The tomatoes are still in his hands.

"I wonder which is sweeter?" he repeats.

He hands me the tomatoes.

Confused, I look at them and then protest,

"But Grandpa, you haven't answered my question."

He's 70 again.

With a knowing and playful smile he asks,

"Where are your feet when you try?" 


\section{Table of Contents}

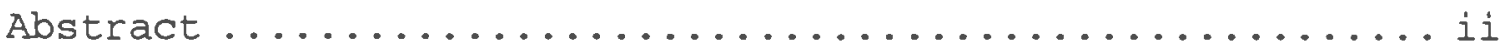

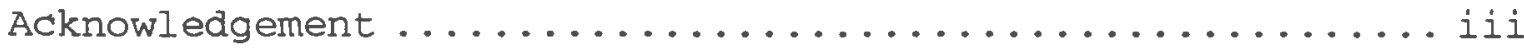

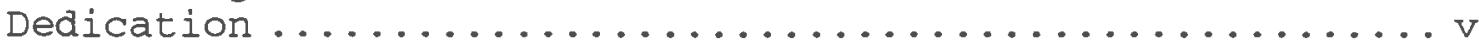

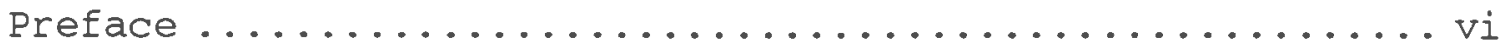

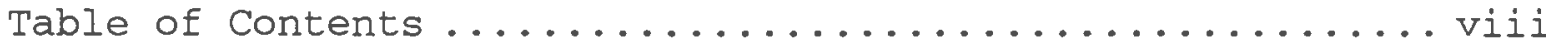

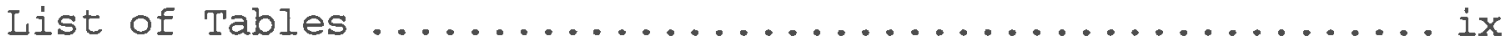

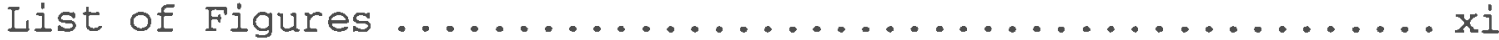

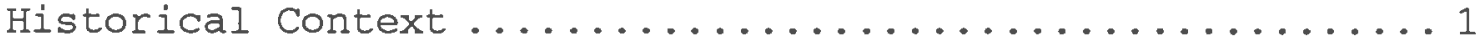

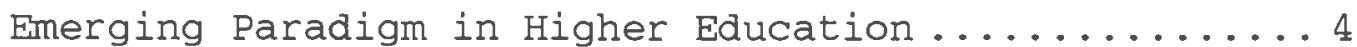

Literature Review ............................. 8

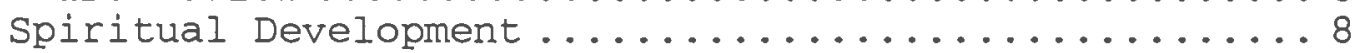

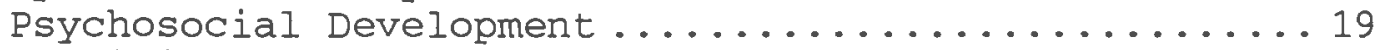

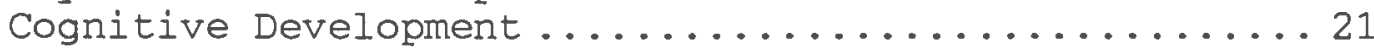

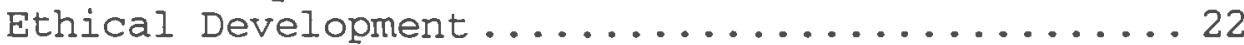

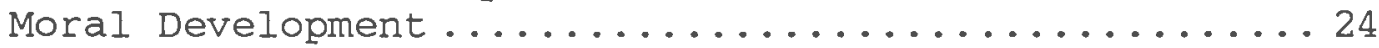

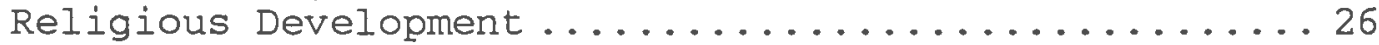

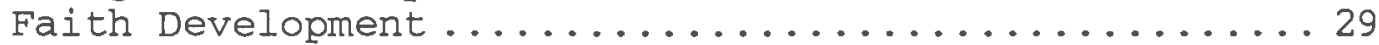

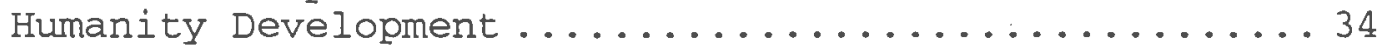

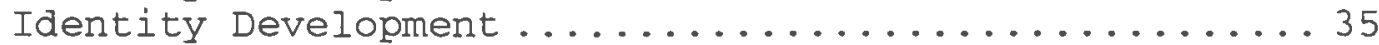

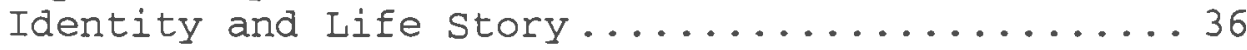

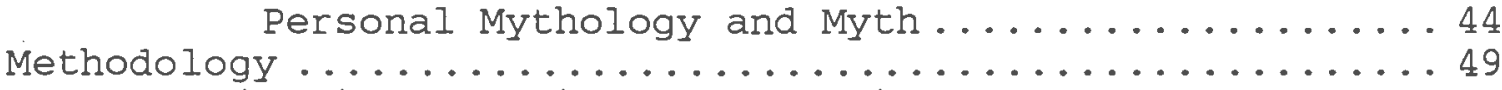

Implications of Literature Review for Methodology ... . 49

Descriptive, Naturalistic, Qualitative............ 51

Myth and Metaphor

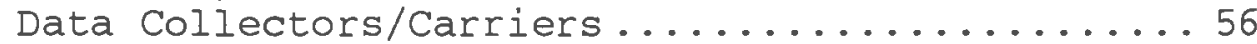

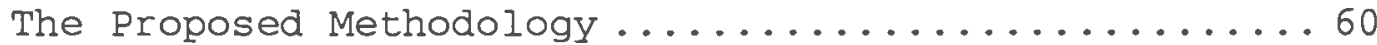

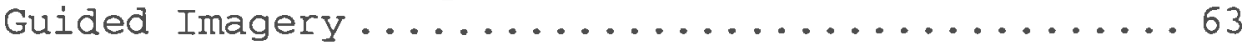

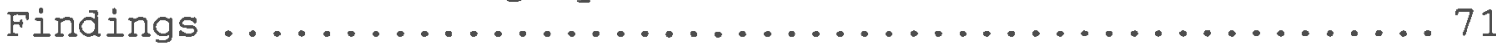

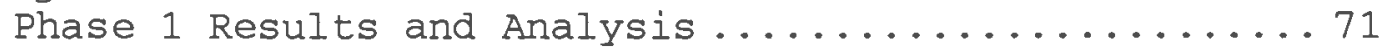

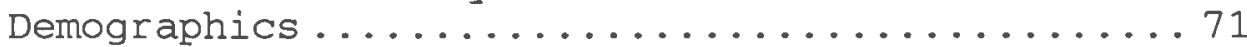

Myers Briggs Temperament Indicator...................... 73

Elkins' spiritual orientation Inventory........74

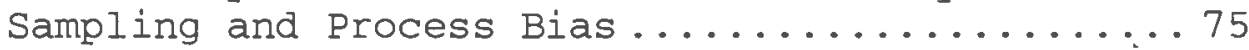

Within Groups

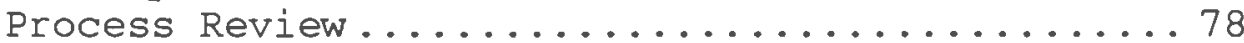

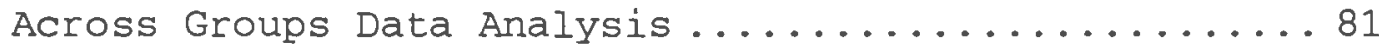

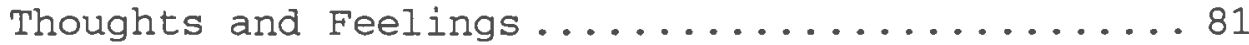

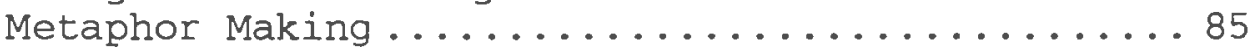

Within Groups

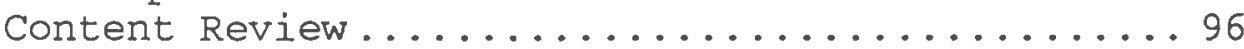

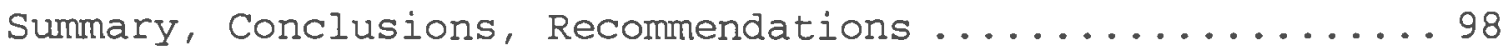

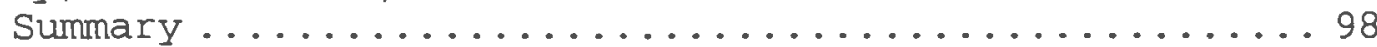

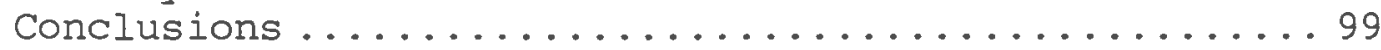

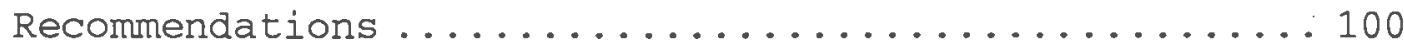

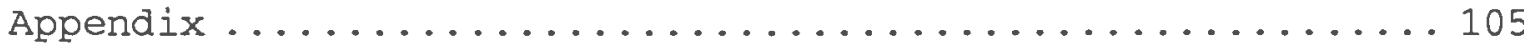

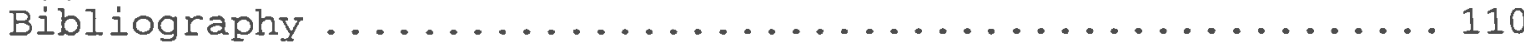




\section{List of Tables}

Table 1 Kuh et al 2001 Paradigm:

old Story/New Story

Table 2 Comparisons of Assumptions about Student Development: Conventional/Emergent

Table 3 Spiritual Orientation Inventory Subscales 17

Table 4 Erik Erikson's Stages of Development 19

Table 5 James Marcia's Identity Status'. 20

Table 6 James Fowler's

Stages of Faith Development $\quad 30$

Table 7 McAdams Life Story Model of Identity 41

Table 8 Distribution of scores on the structural complexity of religious ideologies... 42

Table 9 Classification of narrative forms 47

Table 10 Some means of manipulating narratives to achieve change

Table 11 Axiomatic differences between Positivistic and Naturalistic Research

Table 12 Criteria for Trustworthiness in Naturalistic Inquiry.

Table 13 Qualitative Data Analysis Model

Table 14 Phase 1 Data Collection:

Develop "Seed" Metaphor

Table 15 Hero Cycle: Guided Image/Myth Template

Table 16 Demographic, MBTI and SOI

Profile of Phase 1 Groups

Table 17 Activity Profile of Phase 1 Groups 76

Table 18 Comparison of Consensus Clusters 82

Table 19 Phase 1 Data Adjectives:

Involvement \& Elation Ratings 
Table 20 Comparison of Principal Metaphors and Consensus Metaphors

Table 21 Comparison of Metaphors by Thematic Category Across All Sessions

Table 22 Percent of Metaphors by Thematic Category

91

Table 23 Comparison of Inside the Metaphor Content 93 


\section{List of Figures}

Figure 1 von Eckartsberg's Psychocosm

Figure 2 Humanity Development:

A tentative integration

Figure 3 Components of Data Analysis Interactive Model

Figure 4 Phase 1 Data Collection and von Eckartsberg's Psychocosm

Figure 5 Working Definition of Spirituality 


\section{Historical context}

"... the ills of the human race will never disappear until by God's gift those who are sincere and true lovers of wisdom attain political power, or the rulers of our cities learn true philosophy."

About 395 B. C., in the conviction that through a somehow gifted relationship with God, humans can acquire wisdom and go on to serve others, Plato established his Academy. Considered Europe's first university, its students were disciplined in mathematics, astronomy, music, logic, politics and ethics. Plato's Academy continued for some nine hundred years and was closed by the Emperor Justinian in 529 A. D. (Loomis, 1942)

In relating western higher education's transitions from Greek to Roman to Medieval times, Butts ${ }^{1}$ describes the evolution of the Liberal Arts curriculum as recorded by the Roman Capella (4th Century A.D.). Capella's compendium of knowledge "happened to be the one that the medieval Christian Church adopted". This included the trivium (grammar, rhetoric and logic) and the quadrivium (arithmetic, geometry, astronomy and music) because Capella wanted to retain

1 Butts, R Freeman, Assistant Professor of Education, Teacher's College, Columbia University. This work is primarily devoted to the development of what had come to be known as the Liberal Arts Curriculuum and the efforts over time including his to bring more 'progressive' and 'inclusive' perspectives to higher education. 


\begin{abstract}
"those arts which would interest a group of celestial beings. ... [H] e did not include the natural or mechanical sciences, as he understood the terms, because they were so closely related to material and mundane interests that they were not suitable for spiritual and therefore 1 iberal beings." (Butts, 1939, p.25)
\end{abstract}

From that point through the mid 19th century, the history of European Higher Education reflected the presence and relative strength of man's notion of and relationship with God, his religious beliefs and practices and the influence of institutional religion on administration, faculty and students. For most colleges and universities, the period between 1750 and 1850 saw the replacement of Renaissance and Reformation consciousness with the scientifically based perspectives of the Enlightenment. (Butts, 1939, Clapp, 1950, Kuh, 1978)

The Enlightenment shifted the emphasis of intellectual activity from a hierarchy favoring Theology and Metaphysics to one in which Physical Sciences and the study of the positive held primary sway. German schools embraced Enlightenment concepts and evolved a departmentalized curriculum with a specialized professoriate dedicated as much to the pursuit of knowledge and research as to teaching. This contrasted strongly with the English schools where, for example, at Oxford and Cambridge "each tutor was ... responsible for the entire liberal education and mental and moral discipline of his students.... [and] ... The college authorities undertook to determine the whole moral, physical and intellectual life of the student." (Butts, 1939) 
American colleges and universities had significant roots in the English tradition, but the relatively high degree of religious tolerance of the colonies coupled with wider economic opportunity was also fertile soil for the German system. Though there was still a need for liberally educated clergy and political leadership, the rise of commerce and capitalism also demanded educated people with knowledge of practical, applicable matters. With the establishment of the Land Grant Colleges and Universities and the decline of the power of clergy in private University faculty and administrations, the German system, favoring specialized research oriented faculty, became more widespread.

It may be said that the student Development profession came into being when this changed. According to Kuh, this shift took place in 1870
"when Harvard's president delegated to the dean responsibility for student's deportment and their spiritual and moral development,... [and since then] ... attention to the student as a "whole person" ... has been the raison d'etre of student affairs work. (p 253, 1987, citing Williamson, 1961).

A characterization of the relationship between Academic and student Development perspectives as they have since evolved may be drawn from two more of Kuh's citations.

An emphasis on intellectualism (manifested as dualism and cognitive rationality) has dominated American higher education since the 19 th century and has worked against personal concern for students on the part of the faculty. (p.256, 1987, citing American Council on Education, 1949) 
and

In contrast, advocates for student affairs and liberal education acknowledge the importance of values, emotions, and personal growth issues and argue for a holistic perspective of students' development in which the intellect and the affect are psychological domains of equal importance. (p. 256, 1987, citing Brown, 1972)

\section{Emerging Paradigm in Hiqher Education}

In looking to the 1990's and beyond, Kuh and others (1986) predict that major shifts are underway. In a context of increasingly uncertain and uncontrollable economic conditions, these changes will include:

- the makeup of the population served by higher education

- our understanding of the knowledge of the natural world (including humanity) that is sought and taught at colleges and universities

- the way we come to discover, understand and interpret this knowledge especially in the fields of sociology, psychology and education.

By the $1990^{\prime} \mathrm{s}, 50 \%$ of Higher Education students are expected to be part-time, over 25 years of age and commuters. Due to higher birth rates in the '70's, significantly larger numbers of African and Hispanic Americans are expected to be enrolled. (1986, citing Hodgkinson, 1985)

Heisenberg's Indeterminancy Principle, the dual nature of light, the multiple personality type concepts derived from Carl Jung's work and multiple role constructs of Transactional Analysis are cited from Physics and Psychology as examples of the knowledge which is representative of and emerging from the new, post positivist paradigm. 
It is suggested that these emerging realities are defined contextually, by when and by whom they are observed and cannot be "measured" in the positivist, objective sense of the word. (Kuh et al.,1986)

Through the projection of contrasts between an old Story and a New Story, Kuh et al. present a comprehensive view of the Paradigm and its implications for the Profession. Table 1 expresses the qualities of the two stories.

\section{Table 1}

Kuh et al 2001 Paradigm: Old Story/New Story (1986)

\begin{tabular}{ll}
\hline \multicolumn{1}{c}{ Old Story } & \multicolumn{1}{c}{ New Story } \\
Student affairs work is: & Student affairs work is: \\
- Objective & - Perspectival \\
- Simple and reductionistic & - Complex and diverse \\
- Hierarchic & - Heterarchic \\
- Mechanical & -Holonomic \\
- Determinate & - Indeterminate \\
- Linearly Causal & -Mutually shaping \\
-Assembled & -Morphogenetic \\
\hline Table adapted from Clark (1985) and Schwartz and Ogilvy (1979). \\
\hline
\end{tabular}

Roth and McMahon have abstracted several of Kuh et al. perceptions of the contrasts between the Conventional and Emergent Paradigms as they relate to specific areas of interest to Student Development. (See Table 2 below) 


\section{Table 2}

Comparison of Assumptions about student Development: Conventional/Emergent Kuh et al 1987

Conventional

- Human Development is continuous, patterned, orderly, predictable and cumulative.

\section{Emergent}

- Some features of

development (first order development) seem to be patterned and orderly. Other features (second-order development) are spontaneous and unpredictable.

- Interventions (programs, educational materials, etc.) can be designed to intentionally facilitate development.

- Interventions can be

transported -with

other settings.

- Human development theory describes, predicts and explains students' behavior.

- Development cannot be systematically influenced by external events or actions; mutual shaping by environments and people is acknowledged.

- Circumstances peculiar to a particular context or behavior setting preclude use of interventions across settings.

- Human development theory cannot account for or explain all behavior, and its use may modifications - for use in exclude recognition of behavior not acknowledged by the theory.

- Explanatory power of theory can be improved if more advanced analytical techniques are used to study students.

- A balance of challenge and support is required for development to occur.
- "Bootstrap" approaches or partial, ad hoc theories of student behavior and

development are useful for attempts to account for behavior in a particular setting.

- Development results from a variety of mutually shaping events: direct causal influence of challenge and support actions cannot be assumed.

Table after Roth and McMahon, 1989

Consistent themes within the emerging paradigm project an unfolding drama in which diverse and self developing students interact with an ambiguous and indeterminate environment. Co-starring in the drama is a Profession which is becoming aware that, through the alchemy of mutual 
shaping, holonomics and heterarchy, it can make a difference. At the same time it is no longer certain that it can fathom, in a systematic way, the mystery of why and what should be done for, with or to whom in the emerging when and where. An example of this emerging reality may be the ways in which sincere and dedicated Professionals perceive and respond to the inevitable competition arising among the complex ecology of interests threatened by funding cutbacks. An indication of the curricular impact the "New Story" can have in Higher Education may be exemplified by the alterations Stanford has made in its 'Western Civilization and Culture' program which is now to be known as 'Culture, Ideas and Values',

the yearlong mandatory freshman program carries a directive to provide "substantial attention to issues of race, gender and class". ... [a faculty] enthusiast ... calls it "a more globally oriented course" that "recognizes at once the increasingly heterogeneous makeup of the country's college student population and America's entanglement in a world economy over which it can no longer exercise the control it once enjoyed." (Pg. B-1, Irving, Aug. 27, 1989) 


\section{Literature' Review}

Spiritual Development

Much has been written in response to calls for attention to the whole student. Embracing Erikson's psychosocial stage model in the main, Student Development Professionals have seen theories of Moral, Faith, Identity and Ego Development evolve to broaden and deepen their understanding of students. (Delworth and Hanson, 1980)

Writing on spirituality from within the profession, Collins, Hurst and Jacobson (1987) have called for higher education to give students

the same opportunity to attain spiritual development as they are given in all other areas related to student development in the college years. (p.274)

Defining spirituality, ("a person's relationship with God") in contrast to Religion, ("an institutional mechanism"), the authors further suggest that spiritual matters are not discussed in a professional or institutional mode due to a concern for separation of church and state. Contrasts are drawn between the openness and response the profession has given to feminism, sexual preference, minority issues and political activism and the reservation with which spiritual matters are handled. Notwithstanding this perception, the belief is expressed that

Spirituality can be distinguished from other areas of student development. ... [Spirituality] does not lend itself to scientific study alone... rests on the balance of faith and experience, on both revelation and reason. ... [and] that new methods of investigation and scholarly inquiry be 
considered that can be adapted to the topic of spirituality in higher education. (Collins et al., p. 275)

In a paper presented at the 1989 ACPA national conference Roth and McMahon note the erosion of academia's concern for spirituality "just as many students have become more interested in this dimension of their lives". Integrating the perspectives of Erikson, Kohlberg, Gilligan, Fowler and Westerhoff, the program, entitled "Visions of Koinonia ${ }^{2}$ : The Spiritual Development of College Students", sought to provide examples of successful programs "designed to enhance spirituality while celebrating a diversity of beliefs". (ACPA Program Guide, 1989, p.12)

The program suggested several possible connections between Spiritual Development and Student Affairs including Wellness, Development Theory, Ethical Leadership, Appreciation of Diversity, Community Development, Social Justice and Environmental Issues and Organizational Development. (Roth and McMahon, 1989)

Several researchers (Archer, Probert and Gage, 1987, Emmerling, personal communication, 1989 and Hettler, 1980) have discussed Wellness in relation to college and university students. Emmerling reports current norms on the most widely known model for wellness, the Stevens Point Life Assessment Questionnaire (LAQ) developed by Hettler (1980). Defining wellness as "an active process through which the individual becomes aware and makes choices toward a more successful

2 Greek for "community" 
(healthy) existence", the LAQ assesses six dimensions including the physical, occupational, intellectual, social, emotional and spiritual. Using a 5 point Likert scale ranging from 'almost never' to 'almost always' subjects respond to 14 questions regarding their spiritual life and values. Emmerling (1989) reports that the most recent cross sectional study of traditional age students shows an increase in the percent of positive spiritual attitude scores as age increases from 18 to 25. Females demonstrate a range of scores approximately $10 \%$ higher than males.

In an effort to assess student attitudes towards wellness, Archer et al. (1987) asked 3,190 students from 11 colleges and universities to rate each of Hettler's six wellness dimensions on a 5 point likert Scale as to the extent each affected their health and wellness. This was a cross sectional study in which $96 \%$ of the subjects were of traditional age. The Spiritual dimension was defined as "philosophical or religious pursuit of personal meaning". Students reported their perception that the Physical dimension (nutrition, exercise, sleep, safety) most affected their wellness and that the Spiritual had the least effect. (1987)

Canda (1986) notes that a need has developed among the social work profession for the development of "an understanding of spirituality that is not limited in scope to any single belief system". Citing the historical trend toward the detachment of that profession from sectarian 
institutions and ideologies, since the 19th century, Canda suggests that the field "neglected specific consideration of the spiritual aspect of human needs and experience". Canda's research utilized qualitative, descriptive methodology and involved literature analysis exploring Buddhist, Christian, existentialist, Jewish and Shamanic perspectives. The conception of spirituality which evolved is seen as

the gestalt of the total process of human life and development, the central dynamic of which is the person's search for a sense of meaning and purpose through relationships between self, other people, the nonhuman world, and the ground of being (as described in theistic, nontheistic, or atheistic terms). (p. 147)

In a crossectional study of the membership of the

California State Psychological Association, Shafranske and Gorusuch (1984) developed the following working definition of spirituality:

... spirituality is "the courage to look within and to trust". What is seen and what is trusted appears to be a deep sense of belonging, of wholeness, of connectedness, and of openness to the infinite. (p. 233)

Also cited is Batson \& Ventis' (1982) assertion that "religion is the confronting of existential questions" and James' (1902) view that

"religion and/or spirituality is qualitatively more than the confronting of such existential issues and must include a vision of the divine or a transcendent perspective". ( $p$. 237)

Taking into account the combination of interior, existential and transcendent dimensions implicit in their 
definition and elaboration, analysis of a research sample $(\mathrm{N}=272,70 \%$ male, Mean age 48.8) showed that the majority of members did not belong to an organized expression of religion but that the majority did express the belief that some form of spirituality is relevant in their personal life and in their clinical practice.

Rolf von Eckartsberg (1981) constructed a synthesis of cognitive maps or graphic representations of "theopsychologies" from both Eastern and Western traditions. His 'map' incorporates the models of Frankl, Smith, Swami Rama, Rosenstock-Hussy and Wilber. Their work is seen as understanding "the human individual as a spiritual creature open to the reality of the divine". (p.66)

von Eckertsberg's synthesis is represented by a 'map' in which the personal 'Psychocosm' is shown as a pyramid embraced in an 'Infinite Divine Psychic Energy Field'. The levels or planes of this pyramid are represented in Figure 1. 


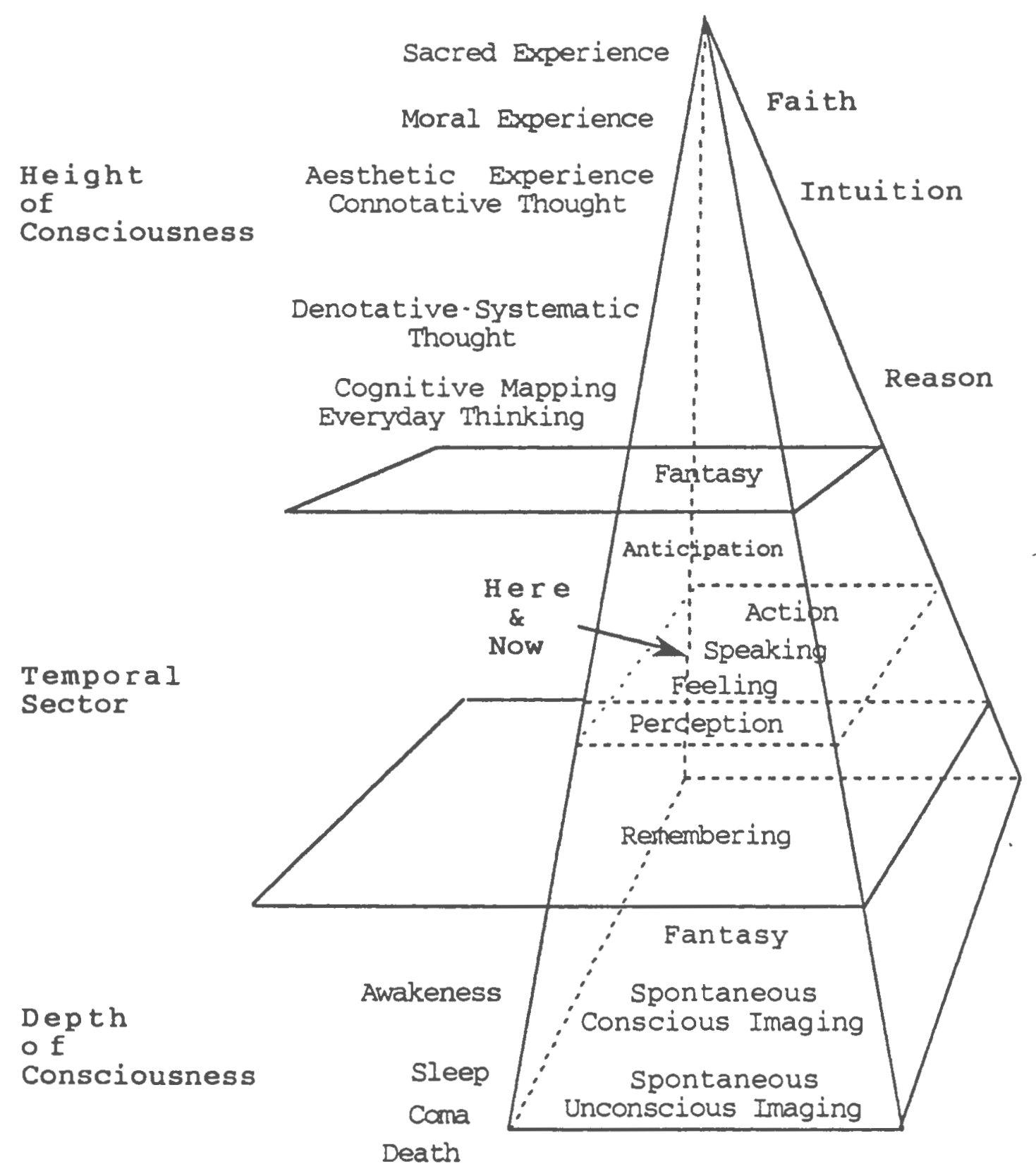

Rolf von Eckartsberg (1981) 
The central or middle sector of the pyramid represents the person and his temporal or existential situation bounded above and below by Anticipated and Remembered existence. The space described above the temporal sector at the Apex of the pyramid can be understood as the height of consciousness dimension.

The apex also reflects the intensity or density of consciousness, the degree of vitality of the person, and the experience of highest value and being. (p. 67)

Descending from the Apex to the Temporal are the beyond space and time worlds of Sacred, Moral and Aesthetic Experience and the realms of Denotative-Systematic Thought, Cognitive Mapping and Everyday Thought. Located both just above Anticipation and just below Remembering in the Temporal space of the Psychocosm is the domain of Fantasy, the "as ifs" and "what ifs"

... [where] one can change his or her existential limitations, finitude, and facticity, and one can attribute to oneself all the qualities desired. We act as if we are omnipotent, omniscient, and omnipresent, with self-attributed qualities in ... a storehouse of potential riches and also a 'magic theatre' of seduction and delusion. (p. 76)

Beneath Memory and Fantasy is the domain of Spontaneous Conscious and Unconscious Imaging.

The open base of the pyramid represents depth of consciousness, which manifests psychologically as imagery arising from the various regions of the personal and collective unconscious ... accessible through the "royal road to the unconscious": dream experience and dream interpretation. (p. 67) 
This realm, "discontinuous with space and time" is the

... underworld of the psyche ... in the realm of the eternal ... in the basic psychic reality that is formed by myth and divine figures ... [and] below this level there is narcosis, coma, and death, the ultimate border areas of human depth consciousness themselves grounded in the infinite divine psychic energy field. ( $p .77$ )

of further note in von Eckartsberg's synthesis is his conviction that

... [theo-psychologists] write from a sacred worldview and consider the person-world relationship as under God... The personal and communal way of life is founded in the historically unfolding story of our community. In recognizing the spiritual and religious dimension in us, the theo-psychologists present a richer picture of the essential dimensions that are needed to ... represent man in his existence as a full human being and an historical person. (p. 66)

The notion of Mind developed by Wilber is helpful to an understanding of von Eckartsberg's concept of the Infinite Divine Psychic Energy Field. Wilber's idea of the Mind incorporates the Hindu and Buddhist senses of "ultimate reality and the ground of Being". (von Eckertsberg, 1981, p. 56) For Wilber,

"Mind ... [with a capital M to distinguish it from the apparent plurality of 'minds']... is what there is and all there is, spaceless and therefore infinite, timeless and therefore eternal, outside of which nothing exists. On this level, man is identified with the universe, the All-or-rather, he is the all."

(Wilber, 1977, cited in von Eckertsberg, p.56) 
Elkins and others, (1988) report an effort to define, describe and measure a humanistic spirituality "of those not affiliated with traditional religion". The authors note that

Religion has been the mother of the world's greatest spiritual giants, the 'best of the species' in the area of spirituality. At its best, religion is the incubator and reservoir of the world's most vital spiritual values. A humanistic approach to spirituality is at variance only with narrow religion that would claim a monopoly on spirituality and would refuse to recognize its human and universal nature. (p. 8)

Wilber addresses the issue of narrow and exclusive religion in Spiritual Choices. The developmental model expressed in his spectrum of consciousness is used as a frame of reference for assessing the authenticity and legitimacy of various religious groups and their impact on individual development. This suggests a hierarchy of religions rising from Prerational through Rational to Transrational. (Anthony, Ecker and Wilber, 1987)

Citing Maslow (1970) and Dewey (1934), Elkins (1988) asserts that "spirituality is a human phenomenon and that it is more basic than, prior to, and different from traditional expressions of religiosity" This phenomenon requires "assessment approaches that would tap 'awareness of and interest in, the continuing, recurrent, permanent problems of human existence" ". (p. 6, quoting Yinger, 1970)

The authors propose a definition of humanistic spirituality synthesized from "implicit descriptions" contained in the works of William James (1958), Carl Jung (1933, 1964), Abraham Maslow, (1962, 1966, 1970, 1971), 
Rudolph Otto (1923), John Dewey (1934), Gordon Allport (1950), Mircea Eliade (1959), Martin Buber (1970), Erich Fromm (1950), Viktor Frankl (1963) and others.

Spirituality, which comes from the Latin, spiritus, meaning "breath of life", is a way of being and experiencing that comes about through awareness of a transcendent dimension and that is characterized by certain identifiable values in regard to self, others, nature, life, and whatever one considers to be the Ultimate. (p. 10)

From this definition a nine component construct was derived which guided the development of a spiritual Orientation Inventory. The inventory's nine subscales are shown in Table 3 .

\section{Table 3}

Spiritual Orientation Inventory Subscales Elkins et al, (1988)

\section{Subscales}

Transcendent Dimension

Meaning and Purpose

Mission in Life

Sacredness of Life

Material Values

Altruism

Idealism

Awareness of the Tragic

Fruits of Spirituality

An administration of the spiritual Orientation Inventory (SOI) to 24 adults nominated by a panel as "high spirituals" and 96 graduate students showed that eight of the nine subscales differentiated significantly between the two groups in the specified direction. (1988, citing Lauri and Elkins, 1988). 
Elkins reports that the SOI will be normed and available for large scale administration and computer scanned scoring by Fall of 1990. He indicated that some 75 inquiries have been received from non-sectarian colleges and Universities throughout the country. (Personal Communication, April 19, 1990)

An assessment measure for spiritual development outcomes described by Cureton, Ebbers and Bole at the 1990 annual meeting of NASPA is based on Fowler's Faith Development model. The forced choice instrument was administered to more than 400 undergraduates at a midwestern Christian college. Cureton indicates that the measure assesses religious behavior, belief and perceptions. Results suggest that undergraduates will seek non-clergy spiritual mentors and prefer para-religious activities to church attendance. No gender or ethnic bias is apparent, though a slight difference was noted in the direction of rural versus urban origins. A qualitative adjunct to the instrument is now being developed. (Personal communication, March 21, 1990)

Acknowledged as a significant aspect of the whole person and a person's wellness, Spirituality has become the subject of serious study by the profession. Hettler, Elkins and Cureton have developed quantitative approaches to its assessment. 


\section{Psychosocial Development}

Erik Erikson's theory of psychosocial human development describes a hierarchy of eight chronological stages through which an individual grows. The creative interaction among internal resources and needs and external demands and challenges stimulates the growth while making use of the skills developed in the earlier stages. The focus of this process is the development of and continuing maintainence of Identity. A synthesis of Erikson's thought regarding identity is proposed by Widick, Parker and Knefelkamp. (1978)

The person has a subjective core self-image which provides continuity and sameness; put simply he knows who he is and can envision those qualities which are most central to his existence. With a subjective sense of self, the person can look back and recognize himself in the child he was ten years ago, or look forward and fairly accurately predict what he will be like in the future (p. 7)

As Table 4 indicates, the college years for a traditional age student are central to the task of Identity formation and are represented by Erikson's Stage 4. (Widick, Parker \& Knefelkamp, 1978)

\section{Table 4}

Erik Erikson's Stages of Development

AGE
$0-1$
$2-4$
$5-6$
$7-12$
$13-21$
$21-35$
$36-60$
$61+$
STAGE

I Trust vs. mistrust

II Autonomy vs. shame and doubt

III Initiative vs. guilt

IV Industry vs. inferiority

$v$ Identity vs. role confusion

VI Intimacy vs. isolation

VII Generativity vs. stagnation

$61+$

VIII Integrity Vs. despair 
In applying Erikson's concepts to empirical study, James Marcia used structured 30 minute interviews with 800 college age students. His research resulted in a model of four possible identity statuses or outcomes. Table 5 shows each as it reflects the coping style expressed by students faced with the identity task. The statuses are not fixed characteristics or traits. Rather, they may be viewed as a "sequence of stopping off points along the identity resolution path". (cited in Widick, Parker and Knefelkamp, 1978)

\section{Table 5}

James Marcia's Identity Status'

\begin{tabular}{cccc} 
& & & Achieved \\
Foreclosed & Identity Diffuse & Moratorium & Identity \\
\hline - No Crisis & - No Crisis/Past & $\cdot$ Crisis & Crisis \\
& Crisis & Experienced & Experienced \\
- Commitments & $\cdot$ No Commitments & $\cdot$ No Commitments & - Commitments \\
\hline
\end{tabular}

For Marcia, crisis refers to the times when an adolescent is "actively choosing among alternative occupations and beliefs. Commitment refers to the degree of personal investment the individual expresses in an occupation or belief". (p.119, 1966).

Though his initial work studied only males, later work (Marcia \& Friedman, 1970, Marcia \& Miller, 1980, Scheidel \& Marcia, 1985) did study females. This work suggested that some gender differences may exist, particularly in the area of the Foreclosure status (1970) and the relationship between intimacy and the achieved identity status (1980, 1985). Interestingly, the 1980 study compared scores on Marcia's 30 
minute interviews with those on the Inventory of Psychosocial Development (IPD) (Constantinople, 1969, cited in 1980) for 29 mature women aged 21 to 59. Results indicate that

Identity Achievement women scored significantly higher than women in the other statuses on all IPD stages except for intimacy and trust; on these two variables, they scored about the same as Foreclosures, and these two statuses together scored significantly higher than did the others. Identity Diffusion women scored lowest of the statuses on all IPD variables. On 6 out of 7 IPD variables Foreclosures were more similar to Achievements than were Moratoriums--a contrast with findings for men on similar measures ... (p. 2)

\section{Cognitive Development}

While Pychosocial theories of development deal with what concerns and decisions students have and are making, the Cognitive developmental theories consider how students will process that information and experience and what shifts in reasoning take place. The work of Piaget is at the core of these theories. Three assumptions are inherent in Cognitive Developmental theory.

First, is that a Structural Organization consisting of "'schemes', 'conceptual systems', 'personal constructs', 'forms', 'styles', 'plans' [or] 'programs'" exists (King, 1978, p. 37) through which humans filter or interpret the information they receive from the outside world. The structure of the thought processes in particular, may be inferred through studying behavior.

Second, these structural organizations evolve in a Developmental sequence that is hierarchical and generally 
invariant. Each stage represents a qualitatively different way of thinking and the highest stage "is an operational definition of human effectiveness in that it spells out the 'most adequate' mode of processing information or of interpreting stimuli." (p.36) Interactionism is the third assumption governing cognitive development theory. The environment's ability to create stimuli which challenge a current structure's capacity to handle the new information is critical to the process. In attempting to adjust to the "dissonance or disequilibrium" (p, 36) created, an individual reorganizes, modifies or replaces the structure to accommodate the increased complexity.

King notes three further contributions of Piaget to Cognitive Development theory. These are his observations that "development proceeds at an irregular rate", that once a stage is achieved,

[t]here exists a process of within stage development ... in which the capacity of the person to use his highest stage operations is gradually expanded to include a wider range of "content" areas. (p. 37)

and that for some stages "[a] major part of the developmental process includes 'decentering', the shifting of focus from self to the larger world". (p. 37)

\section{Ethical Development}

William Perry has constructed a cognitive stage theory of Ethical and Intellectual Development which consists of nine positions representing four general orientations to the perception of knowledge and other points of view. Perry's 
model moves from Dualism to Multiplicity to Relativism to Commitment in Relativism.

Dualists see matters as black or white, right or wrong. This perspective is accompanied by the belief that an absolute authority or teacher exists whose job it is to zommunicate these absolutes to the student.

Multiplists accept diversity and the idea that others have a right to another opinion. The existence of absolutes and the authority allow for this. Recent speculation suggests that Multiplists do not exist as a separate entity from Relativists.

In Relativism, the student sees beyond acknowledging differences to their validity as part of a larger whole. All views including the authority's are relative and contextual. Absolutes are special cases of this diversity.

With Commitment in Relativism, the student establishes a commitment in some area and through experiencing its implications develops an understanding of responsibility for and to the ethical and intellectual positions held. This ongoing development results in an affirming harmony among identity, commitments and lifestyle.

Kurfiss has demonstrated that Perry position scores increase with years in college (1975, cited in King, 1978b). This research reports average position scores by class of 2.84 (Freshmen), 3.13 (Sophomores), 3.55 (Juniors) and 3.48 (seniors). 
Perry's work may provide a cognitive frame of reference for the emerging views of the ways in which students perceive, experience and value relationship with self and other.

\section{Moral Development}

Lawrence Kohlberg and Carol Gilligan have studied Moral Development .

Kohlberg's construct involves three levels, Preconventional, Conventional, and Postconventional, Autonomous or Principled. Each level consists of two stages which describe how students see themselves in relation to others and what perceptions and attitudes inform their moral decisions.

Preconventional, Stage 1 behavior exhibits a punishment and obedience posture reflecting concern for self. Preconventional, Stage 2 involves self serving concern for another which can be expressed as "you scratch my back and I'll scratch yours".

Conventional, Stage 3 reflects a movement into concern for groups, conforming to group norms and living up to what one perceives as expected. Conventional, Stage 4 exhibits growth in terms of concern for the safety and preservation of society through what is essentially a "law and order" orientation.

Principled, Stage 5 behavior involves "doing what is right, regardless of the rules". With this perspective an individual would feel an obligation to contract, law and 
obligations entered into freely while being concerned for some specific rights such as Iife and liberty no matter what the rules. Principled, Stage 6 behavior is based on the belief in valid, universal, moral principles. If laws are seen to violate these principles, one adheres to the principle. Justice, Equality and respect for everyone's dignity as individuals are principles included at this stage.

In a review of research on Kohlberg's model Smith reports that "the predominant mode of thinking among college students in general is conventional reasoning of a stage 3 or Stage 4 type". (Smith, 1978, p. 58)

Smith also notes that Gilligan (1977) reported the concern that Kohlberg's scoring system favors men. (1978) The basis of Gilligan's thesis rests in the fact that the subjects of much of Kohlberg's work were white, middle class males.

From Gilligan's point of view, men learn to separate from relationship with their primary (female) caregivers at an early age and then in adolescence they are routinely launched into identity development through competitive differentiation from their male models and/or peers and a rite of passage which is manifest through some autonomous activity. At a later time, relationship to others, whether as individuals, social groups or the human race as a whole becomes a desired developmental goal. If this higher stage develops it is only after the establishment of a unique and self-centered identity. 
In contrast, the female child is not separated in any physical or symbolic way from the modeling of her primary caregiver. Women are linked to a relational, caregiving model valuing empathy and compassion. Women evolve their identities through exercises in relationship and responsibility while men seem to develop theirs through structured competitions that rely on rules which support fairness, justice and individual rights.

Gilligan suggests a theory of moral development that embraces an ethic of care and compassion as well as of fairness and justice. The theory focuses on transitions involving the central problem of conflict between self and others. Gilligan's model suggests movement through three levels of awareness within this tension: (a) Centered on Self, (b) Goodness as Self-Sacrifice and (c) Care as Universal Obligation. (Gilligan, 1982, Roth \& McMahon, 1989). Given the importance of relationships to the development of college students, potential connections among spiritual attributes and the process of moral development promise significant insights into the way students come to value and experience themselves, their environments and others.

\section{Religious Development}

Worthington (1989) has surveyed the literature on religious, spiritual and faith development across the life span from the perspective of clinical counseling. This work concludes that a developmental structure appears to apply in these aspects of human growth at least through adolescence 
and perhaps young adulthood or Erikson's Stages IV/V. After this, it is suggested that either transition theory or lifeevent models are more reliable predictors of activity and growth in the religious domain.

Worthington gives particular attention to the models of Jung, Allport, and Fowler ${ }^{3}$. Of Jung he notes

Jung (1958, 1973) proposed a system of spiritual and religious development. He was attracted to Eastern as well as Western religions as an adult. According to Jung, during the early years, the human is deeply involved in ego concerns, in rational order, and in logical systems of religion. However, as the person reaches middle age, he or she often is awakened to the need for wholeness and balance in life, which opens the door for religious experience. ( 1989 , p. 567)

Worthington understands Gordon Allport's Theory of Religious Sentiments as a three stage developmental model in which "[r]eligious sentiments are religious beliefs (empowered by affective energies) that lead to consonant religious and secular behaviors". In childhood the person is in the "raw credulity" stage which is characterized as authoritarian, childish and irrational. This gives way to the pervasive doubt of a second stage in which the faith or religion of one's birth is tested. In the third stage

the person henceforth lives with ambiguity, doubt and faith alternating. Some develop mature faith, in which they find more strength in the affirmations of faith than in the doubts. Others develop disbelief, in which doubts predominate. Still others develop doubts and affirmations of essentially equal strength; they are agnostic. (Allport, 1950, cited in worthington, p. 565, 1989)

\footnotetext{
'Fowler's work on Faith Development is described in greater detail below.
} 
Worthington's view of adult religious development would seem to confirm the findings of Oswald and Leas (1987) who studied 21 main line Protestant congregations and the process of newcomer assimilation within them. The study covered 4 years and made use of life story interviews of more than 400 persons who had been members of these congregations for less than three years. Results indicated that prior to joining, $52 \%$ had moved, ten percent became married and the balance were experiencing other major transitions including birth of a child, death of family member/friend, the aging of a parent, a difficult teen, substance abuse by a friend, relative or spouse, a divorce or the breakup of a significant relationship.

In an immediate response to Worthington's article, Hendlin (1989) argues for something more than maturity. Hendlin asserts that the article "is heavily biased toward dualistic, exoteric-mythic, Western institutionalized religion". (p. 617) This leads to his question

Is there room for the concept of personal "enlightenment" in our Western theories, or are "religious maturity" and "faith" all that we are willing to accommodate? (p. 619)

For Hendlin, more exposure to the notions of spiritual and transpersonal as expressed especially by wilber might provide a more balanced and inclusive perspective for the counseling profession.

Roberts (1984) points out that religion has most often been studied from a sociological point of view using 
historical analysis, some experimental design, participant observation, survey and content analysis. In a concluding comment regarding efforts "to formulate empirical research procedures and sociological theories which assume the reality and efficacy of the supernatural" (citing Garrett, 1974 and Paloma, 1982a) Roberts declares

the meaning of a transcendent dimension of life for individuals can never be fully grasped through objective, scientific study.

... [and, citing Paloma (1982b)] scientific empiricism is itself a world view and ... the determinism of the social sciences can dull one's sensitivity to the mystical, intuitive, symbolicimagisitic side of life. (p. 405ff, 1984)

Finally, Robert's quotes Milton Yinger (1970).

No one would claim that the analysis of paint, painter, and patron exhausts the meaning of art; we are becoming cautious about making equivalent claims for the analysis of religion. The scientist must realize that propositions derived from objective study do not exhaust the meaning of things. (p. 406, 1984)

\section{Faith Development}

Through analysis of more than 500 extensive interviews (up to 3 hours long), theologian-developmentalist James Fowler and his associates have constructed and tested a seven stage model of Faith development (1981, 1984, Moseley, Jarvis, \& Fowler, 1986). The interviews explored four areas: Life Review, Life-shaping Experiences and Relationships, Present Values and Commitments, and Religion. (1981) Respondents ranged in age from 3.5 to 84 years with the largest number $(25.1 \%)$ between 21 and 30 . The sample was 
equally divided by gender and was largely white and

Christian. Table 6 presents the model.

\section{Table 6}

James Fowler's Stages of Faith Development

\begin{tabular}{lll}
\hline \multicolumn{1}{c}{ Age } & \multicolumn{1}{c}{ Stage } & \multicolumn{1}{c}{ Characteristics } \\
\hline Prenatal & Primal & - Somatic experience of "threat \\
of negation in ... emergence \\
into life" \\
-experience of "mutuality of \\
need", "roots of confidence", \\
"memories of parental presence" \\
(Fowler, 1984,p.52 ff)
\end{tabular}

For Fowler, "faith is a human universal". It is an imperative invoked by the realities of the human condition 
that include a "universal awareness of death", the need to "make life defining choices under conditions of uncertainty and risk" and a duality encompassing the mundane and "mystery".

We do not live long or well without meaning. That is to say, we are creatures who live by faith. (1984, p. 50)

Developmental and educational psychologists, Rich \& DeVitis, in a broadly based historical survey of moral development theories compare conventional definitions of faith with what they term Fowler's stipulative definition, which helps individuals "in creating conceptions of ultimate reality and answering such questions as, 'What is the meaning of life?'[4]". (1985, p. 105)

Here are some conventional definitions of faith: "firm belief in something for which there is no proof"[5] or "an attitude of belief which goes beyond the available evidence." [ $\left.{ }^{6}\right] \ldots$ It is necessary, then to examine the stipulative definition to ascertain whether Fowler is warranted in employing it in terms of success or failure in generating fruitful and creative ideas ... [for conceiving of and coping with reality].

Faith helps to shield us from our nakedness and provide the courage to face the abyss that surrounds us. It helps us to develop an ultimate environment, a dependable life span. Faith is universal, whether one is a Hindu, Christian, or Marxist. Each person is born with a capacity for faith, but it requires a nurturing environment to grow. Faith is not always religious... [i]t is the way that individuals find coherence and meaning in

4 (Fowler, 1981)

${ }^{5}$ Webster's Ninth New Collegiate Dictionary. Springfield Mass., MerrianWebster, 1983.

6 Reese, W. L.: Dictionary of Philosophy and Religion: Eastern and Western Thought. Atlantic Highlands, N. J. , Humanities Press, 1980, p 166. 
their lives; it is a person's way of relating to others against a backdrop of shared meaning and purpose.

... It is an active mode: a way of trusting, commiting, and relating to the world; and by these commitments ... values are conferred that may be of transcendent worth. Thus linkages are formed with others... [that] are based on trust and loyalty.

... [F] aith itself, according to Fowler, is a way of seeing our life in terms of holistic images; our knowledge begins with images and is stored in images. An image is a vague inner representation [of] one's feeling about a state of affairs. Images, therefore, precede concepts and are deeper than them. ... our first stage of shaping a response is to scan images to discover what we know about something. The world's religions, for instance, evoke the imagery of the ultimate conditions of existence. But because some person's imagery of ... the ultimate conditions of existence ... may be impersonal, indifferent or randomly chaotic rather than structured and coherent does not mean that it is not an image of faith. The opposite of faith is nihilism, not doubt. It is the nihilist who despairs in finding any meaning in life and is unable to image a transcendent environment. (1985, p. 105 ff.)

The rarity of Fowler's Stage 6 Universalizing Faith can be attributed to the fact that it is defined by and through empirical extensions of cognitive developmental theory implicit in the evolution of prior stages, especially stage 5. In fact, very few Stage 6 individuals have been identified. At stage 6, the more narrow egocentric concerns of an individual are

transcended because they are ordered by an allencompassing ideal or vision of the good that is indicative of a sense of relationship to and participation in the whole or totality of being. (1986, p. 177)

In scoring interview responses Fowler seeks to evaluate "the ways in which a subject 'operates' on seven specific 
content areas". These content areas or aspects express primarily cognitive content (Form of Logic, Form of World Coherence, Symbolic Function) or psychosocial as well as cognitive content (Locus of Authority, Social Perspective Taking, Bounds of Social Awareness, Form of Moral Judgment). As Stage 2 progresses to Stage 4 within each aspect, Fowler's developmental view appears substantially grounded in Piaget and Kohlberg.

Within Synthetic-Conventionals, the most common stage encountered in college students, "an intense concern for the building and maintaining of interpersonal relationships" is noted. As Table 6 notes, the theme of conformity versus independence plays an important role in developing the sense of self which emerges during this period.

In 1984, Fowler and his associates began using an optional Life Tapestry Exercise in conjunction with some standard Faith Development structured interviews. Subjects are encouraged to view this biographical exercise as if writing a drama or play. In addition to helping to condition the subject's reflective process for the structured interviews, these tapestries have been useful as validation references for coding specific aspects. (Moseley et al.,1986)

Fowler's work suggests the possibility of considerable overlap among the definition of Faith implicit in his work and the definition of Humanistic spirituality proposed by Elkins and others (1989). Analysis may show that both models measure substantially the same attributes. Analysis of the 
aspects described in the Manual for Faith Development Research (Moseley et al,1986) suggests connections and overlaps in the study of Moral, Identity and Ego development as well.

\section{Humanity Development}

Figure 2 has been developed to provide a frame of reference within which to understand apparent relationships among several aspects of Human Development. These are the focii of Human Development research which are often noted in student development literature and which may bear on the present research.

\section{Figure 2}

Humanity Development: A tentative integration

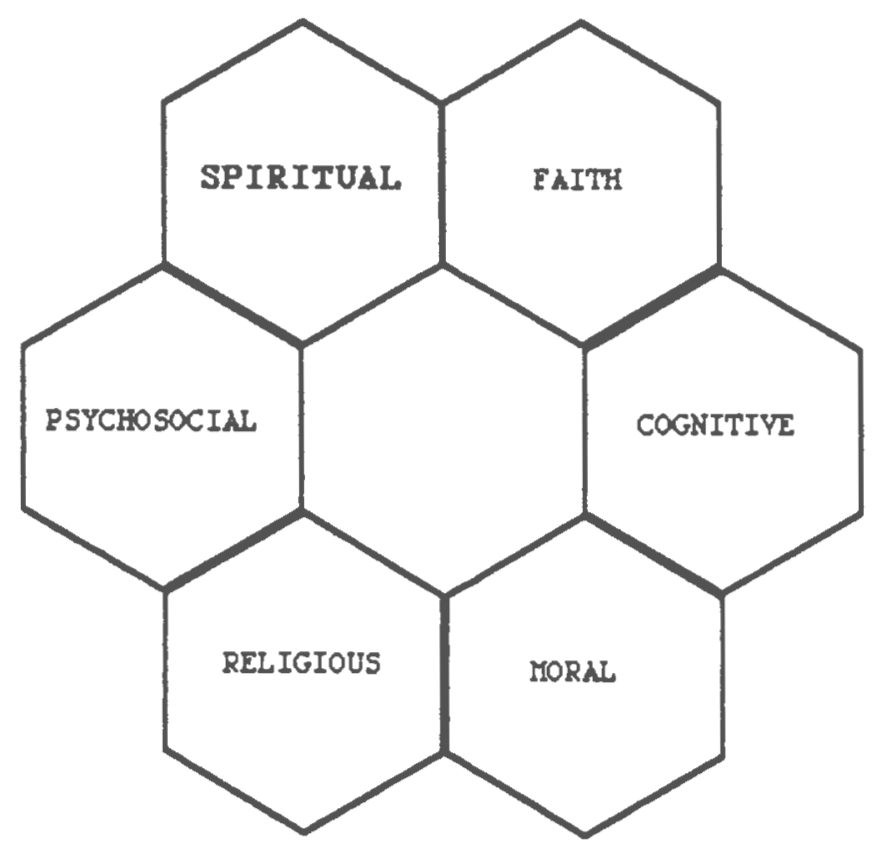


Conceptually, these constructs are seen to be related as more or less cognitive, more or less psycho-social and more or less affective. It may also be useful to understand them as reflecting or refracting aspects of each other. These interconstruct vectors and dynamics are suggested to some extent by the positions of each around the Figure 2's periphery as well as across its central cell.

\section{Identity Development}

Seen in the perspective of the representation shown in Figure 2 above, the literature would suggest that Human Development, especially in the years associated with traditional age college students is the process of Identity Development. The manner in which individuals understand and evolve relationship among self and others and the way in which they make meaning in their life is central to this process.

Developmental Psychologist, Robert Kegan (1982) advances the theory that individuals grow through meaning making in five developmental stages during which environment-self interactions alternately emphasize independence/autonomy or inclusion/community.

This series of balances or truces through which identity evolves can be understood to represent aggregates of meanings about a person's subject-object relations and the "basic organization of the psychological self". A coherent structure incorporating emerging attributes for each balance can be described through a series of emotional, motivational, 
psychodynamic, cognitive and sociomoral filters. (Kegan, 1982, p. 74)

\section{Identity and Life Story}

In an extensive use of biography, McAdams (1985) studied Identity Development in 90 college students and 50 midlife adults utilizing a personological methodology. Personology is
Historically grounded in the writings of Henry Murray (1938, 1955), ... [Personology] has emphasized the study of the whole person in his or her sociohistorical context. In addition, personologists have traditionally adopted biographical approaches to the study of human lives and have often focused their inquiries upon fundamental human motives. Thus, the whole person, biography and motivation are three major themes ... in my own inquiry into the life stories which make up human identities. (p. 20)
McAdams collected life stories by means of lengthy questionnaires incorporated with "identity journals" written over the course of a semester by students in developmental psychology courses. Less comprehensive individual interviews conducted by a graduate student and patterned on the 'identity journal' questionnaire were administered to volunteer evening school students 35 to 50 years of age. Both groups were also given the Thematic Apperception Test (TAT), Washington University Sentence Completion Test (WUSCT) and several other paper and pencil measures.

Citing Grotevant \& Cooper; 1980, Marcia, 1966; and McAdams, Booth and Selvik, 1981, as efforts that have been made to measure the identity formation process, McAdams contends that the question of "the content and structure of 
the identity configuration has been avoided". (p. 17)

Quoting from Erikson's Young Man Luther, he suggests that in young adulthood

men and women come to see... life in continuous perspective, both in retrospect and in prospect, ... selectively reconstructing [the past such that] we do chose our parents, our family history, and the history of our kings, heroes, and gods. (Erikson, 1958, p.112, quoted in 1985, p. 41)

Effectively, this means that to achieve identity is to choose, to create, to fashion a life story. (1985)

In developing his "identity as life-story metaphor",

McAdams suggests that

the identity configuration to which Erikson alludes is a configuration of plot, character, setting, scene, and theme.

Individual identities may be classified in the manner of stories. Identity stability is longitudinal consistency in the life story. Identity transformation - identity crisis, identity change - is story revision...

The problem of identity is the problem of arriving at a life story that makes sense - provides unity and purpose - within a socio-historical matrix that embodies a much larger story ... In this way identity is truly psychosocial: ... a joint product of person and environment In a sense the two write the story together. (p.18)

Having arrived at young adulthood or the latter phases of Erikson's Identity vs. Role Confusion, (Fowler's Synthetic-Conventional) a college student begins to absorb significantly wider ranges of new information in the form of facts and experiences. This new information, either cognitively or affectively shaded, tends to reframe their perspectives and stimulates an initially unconscious and 
perhaps uncritical review of the content of the life story they absorbed and which was principally shaped by authority during what Erikson calls the Industry vs Inferiority period (7-12 yrs) (Fowler's Mythic-Literal Stage).

McAdams (1985) suggests it was at this earlier point that an emerging person learned to ask what being 'good' meant both as a sense of competence and as an understanding of the environment's expectations. As the young person moves through early and middle adolescence, opportunities to begin choosing among occupations and activities or to adapt inherited ideological perspectives are presented. An individual's response to these opportunities determines Identity Status. (Marcia, 1966)

In amplifying the environmental role, McAdams quotes Jerome Bruner. (1960)

[Bruner] writes that the 'mythologically instructed community provides its members with a library of scripts' against which the individual may judge his or her own 'internal drama' ... 'Life, then, produces myth and finally imitates it' (p. $281 \mathrm{ff}$ quoted in 1985, p.18)

McAdams' metaphor of identity as story extends to the story writer or "biographer of self". (p. 19) Citing biographer Leon Edel's assertion

When the biographer can discover a myth, he has found his story. He knows the meaning of his material and can choose, select, sift without deceiving himself about the subject of his work (Edel 1978, p. 2, quoted in 1985, p.19)

McAdams concludes

that when the person finds (creates, constructs) a personalized life myth or story, he or she no 
longer "deceives" the self and world. The story provides a coherent narrative framework within which the disparate events and the various roles of a person's life can be embedded and given meaning. The story provides a pattern for the scattered identity pieces of the protean man. The story is an antidote for bad faith. (p. 19)

McAdams proposes a Life-Story Model of Identity incorporating four components: (1) Ideological Setting or values, beliefs and "faith" and one's "view of the ultimate environment" (quoting Fowler, p. 29, p. 65), (2) Imagoes or characters described as Archetypes and the pantheon of mythology, (3) Nuclear Episodes or critical scenes and (4) Generativity Scripts or "what one hopes to put into Iife and what one hopes to get out of life before one is too old to be generative". (p. 65)

The Life-story Model conceives these components as having more or less structure or Jarrative Complexity. This complexity is seen as being an indication of the stage of Ego development of the story teller. Ego stage is referenced in terms of Loevinger's 10 stage construct. (Knefelkamp, Parker \& Widick, 1978)

Providing thematic content to each component are varying amounts of the motives of Power and Intimacy. McAdams sees the themes of Power and Intimacy operating in something of a dialectic process out of which these motives or "springs of action" (citing James, 1890) synthesize the creativity or generativity in a person's life.

Describing motive as

a personality disposition for the individual

[which] ... serves to energize, direct, and select 
behavior and experience within the context of constraints and opportunities afforded by the environment. (1985, p.71)

McAdams goes on to reject theories which argue that there are many motives (citing Murray, 1938 and McDougall, 1908) or just one motive (citing Adler, 1927 and Rogers, 1951) in favor of those which propose dichotomies and which

imply that humans are, by their motivational nature, beset with conflict, and that the telos of development and therapy is reconciliation of opposites. (1985, p. 73)

In tracing the theoretical family tree of his thoughts relating to the power-intimacy dichotomy, McAdams recalls several ways in which the tension between these manifestations and expressions of human energy have been characterized through the years. He begins with the 5 th century B.C. philosopher, Empedocles' assertion that Love and Strife were the organizing principles through which earth, air, fire and water combined "in different proportions to produce all matter in the world". (1985, p.69)

During the 20 th century, McAdams cites Freud's progression (1900/1953, 1920/1955) from a bi-level motivation concept involving "life-maintenence instincts (such as hunger) and the pleasure-inducing instincts (libido)" to a dichotomy of life instincts (Eros) and death instincts (Thanatos). (1985, p.73)

With perspectives similar to Freud's, McAdams notes that Otto Rank (1936) and Andras Angyl (1941) have proposed motivational dichotomies... . Rank maintained that fear of life and fear of death were the two primary forces in human lives. Angyl 
suggested the need for autonomy and the need for surrender. ... [and] David Bakan has argued that two fundamental "modalities" exist in all living forms. The first agency, refers to the separation of the individual from others and from context; the second, communion, refers to the coming together of individuals and a merger with context. (1985, p. 73, underscoring mine)

Table 7 represents the relationships among the elements of McAdams' Life-Story Model

Table 7

McAdams' Life-story Model of Identity (1985)

\begin{tabular}{|c|c|c|}
\hline Component & $\begin{array}{c}\text { Narrative Complexity } \\
\text { Indicator of ego } \\
\text { development }\end{array}$ & $\frac{\text { Thematic Lines }}{\text { Content of motive }}$ \\
\hline $\begin{array}{l}\text { Ideological } \\
\text { setting }\end{array}$ & $\begin{array}{l}\text { Complex ideology, more } \\
\text { questioning }\end{array}$ & $\begin{array}{l}\text { Intimacy: care, } \\
\text { responsibility } \\
\text { Power: rights, justice }\end{array}$ \\
\hline Imagoes & Integrated imagoes & $\begin{array}{l}\text { Intimacy: communion } \\
\text { Power: agency }\end{array}$ \\
\hline $\begin{array}{l}\text { Nuclear } \\
\text { Episodes }\end{array}$ & More and varied episodes & $\begin{array}{l}\text { Intimacy: love, dialogue, } \\
\text { sympathy, touch } \\
\text { Power: strength, } \\
\text { influence, action, status }\end{array}$ \\
\hline $\begin{array}{l}\text { Generativity } \\
\text { script }\end{array}$ & $\begin{array}{l}\text { Complex script, varied } \\
\text { goals }\end{array}$ & $\begin{array}{l}\text { Intimacy: } \\
\text { Communal generativity } \\
\text { Power: Agentic } \\
\text { generativity }\end{array}$ \\
\hline
\end{tabular}

The identity journals of 78 of 90 students provided the data for study related to the Ideology. The question, in part, invited students to

[d] escribe in as much detail as you see fit your present religious beliefs.... [0] ne need not be a regular church attender to have a well articulated religious belief system. Religious belief can refer to your most basic thoughts and feelings about the universe and the human being's place in it. (p. 287) 
Accordingly, McAdams notes that the ideology being studied is essentially Religious Ideology and that "[f]uture study should extend ... into ideological realms outside the sphere of religion". (1985, p.235)

In developing his construct for indicating Ideological complexity, McAdams drew heavily upon Fowler, Kohlberg and Perry. Each of the 78 respondents were scored on a scale of 0 to 5. Table 8 reflects the scale, the number of responses in each category and the corresponding stage or level from each of the contributing sources.

\section{Table 8}

Distribution of scores on the structural complexity of religious ideologies and their relation to other

\begin{tabular}{|c|c|c|c|c|c|}
\hline Ideological Complexi & Eyn $=78$ & $\%$ & Fowler & Kohlberg & Perry \\
\hline 0 . No ideology & 1 & 1.2 & & & \\
\hline 1. Rules of conduct & 5 & 6.4 & & & \\
\hline 2. Vague beliefs & 19 & 24.4 & $\begin{array}{l}\text { between } \\
2 \& 3\end{array}$ & & \\
\hline $\begin{array}{c}\text { 3. Dogma or creed, } \\
\text { conventional }\end{array}$ & 32 & 41.0 & 3 & $4-4.5$ & $\begin{array}{c}\text { mid } \\
\text { relative }\end{array}$ \\
\hline $\begin{array}{l}\text { 4. Personalized system, } \\
\text { vague }\end{array}$ & 20 & 25.6 & 4 & & \\
\hline $\begin{array}{l}\text { 5. Personalized system, } \\
\text { integrated }\end{array}$ & 1 & 1.2 & & & \\
\hline
\end{tabular}

When the structural complexity of the Religious Ideology of respondents was compared with Loevinger's Ego stages, a high correlation was found between those scoring high in complexity and high in ego development (Stage I-4 and above or Conscientious and above). Conversely, lower Complexity scores reflected lower ego stage development. (Stage I-3/4 
and below or Conscientious/Conformist). The results indicate a highly significant difference for ego stage and complexity. Gender was unrelated to complexity.

McAdams analyzed the same set of answers for reference to an ideology of Rights, Laws and Principles (RLP) corresponding to the Power motive or one of Compassion, Care and Responsibility (CCR) corresponding to the Intimacy motive. This delineation was suggested by Gilligan's (1982) hypothesis that there are two ideological voices which are to some extent related to gender in terms of the sequence in which they emerge in development. McAdams reports the Male score to be "very close to being statistically significant". (1985, p. 241) There was no support for a gender relationship on RLP content.

In terms of content in Generativity scripts, the study showed that a strong correlation existed between high Power motivation assessed via the TAT and "agentic" future scripts. A similar correlation existed between Intimacy motivation and "communion" thematic content. With regard to the level of generativity in Generativity Scripts, McAdams found that among the 50 midlife adults studied,

[those] whose life stories evidenced the greatest concern for generative action in the future tended to score high on power and intimacy combined. (1985, p. 273)

Finally, McAdams found that when comparing the data on Generativity scripts with that of the Nuclear episodes, there were correlations between power/agency themes in future 
scripts and power scores in peak, nadir and positive childhood experiences. This suggests continuity between episodes in the past and the level of action envisioned in the future. Similarly, a significant correlation is found among intimacy/communion themes in generativity scripts and scores in nadir experiences.

Both the content and methodology of McAdams' work may bear strongly on the study of spiritual development. The balance of power and intimacy or agency and communion (in Kegan's terms autonomy and inclusion) would seem to connect in a fundamental way with a person's valuing and experiencing of relationship. The study of student life story (past, present and projected) and the use of evocative images may provide a rich source of data about the state and evolution of Spiritual awareness and development.

\section{Personal Mythology and Myth}

The use of life story in the form of personal mythology in a clinical setting involving more than 2000 clients is reported by Feinstein and Krippner (1988). Their work grew out of research at Johns Hopkins and is organized around the following premises.

1.) Myth making, at both the individual and the collective levels, is the primary though often unperceived psychological mechanism by which human beings navigate their way through life. 
2.) People in contemporary cultures are more capable of constructing distinctively personal mythologies and reflecting upon those mythologies than in any previous period of history - and the need to become conscious of the mythologies we are living out is more urgent than ever before.

3.) By understanding the principles that govern your underlying myths, you become less bound by the mythologies of your childhood and of your culture, and you may begin to influence patterns in your life that once seemed predetermined and went unquestioned. (1988, p. 4)

Feinstein and Krippner (1989) use a five stage approach in their therapy which incorporates guided imagery and journaling. For the purposes of the research contemplated by this proposal, their use of guided imagery as a means of inducing mythological thinking may hold promise.

Joseph Campbell, presents a view of the historic pattern of mankind's mythic sources which would seem to support the second of Feinstein and Krippner's premises. Campbell notes that as humanity has tried to make sense out of its relationship with the Unknowable, (that is, God, the Transcendent, the Ultimate, the Ground of Being, etc.) it has looked to three external sources for its myth making.

First among these was the animal kingdom and second the world of planting. When these orders of creation lost their numinous and mysterious qualities as they came under social control, humanity then looked to the cosmos,

[w] hereupon the great field of instructive wonder shifted - to the skies - and mankind enacted the great pantomime of the sacred moon-king, the sacred sun-king, the hieratic, planetary state, and the symbolic festivals of the world-regulating spheres. (1968, p. 390) 
Campbell goes on to suggest that with the Enlightenment and the demystification of physical science and astronomy followed by humanity's initial conquest of space the role of the Cosmic order as a source of meaning or sensemaking was also lost.

The descent of the Occidental sciences from the heavens to the earth .... and their concentration today, at last, on man himself (in twentiethcentury anthropology and psychology) [has made]. ...man himself ... the crucial mystery. Man is that alien presence with whom the forces of egoism must come to terms, through whom the ego is to be crucified and resurrected, and in whose image society is to be reformed. Man, understood, however, not as "I" but as "Thou": for the ideals and temporal institutions of no tribe, race, continent, social class, or century, can be the measure of the ...divine existence that is the life in all of us. (p. 391)

In an interdisciplinary study embracing comparative religion, the history of religions, anthropology, sociology and myth criticism among others, Bruce Lincoln (1989) has suggested a definition of Myth with relation to History and other narrative forms. Lincoln presents an explanation of how Myth is used by social groupings to define borders, to establish peer relationships and to carry ancestral invocations. Lincoln ranks the narrative forms of Fable, Legend, History and Myth in an ascending order of power based on the valence of the Truth-claims, Credibility and Authority each possesses. Table 9 represents Lincoln's ranking of narrative forms. 


\begin{tabular}{lcccc}
\hline \multicolumn{5}{c}{ Table 9} \\
Classification & of & narrative forms \\
(Lincoln, & B. & 1989, & 0.25) & \\
\hline Form & Truth-Claims & Credibility & Authority \\
\hline Fable & - & - & - \\
\hline Legend & + & - & - \\
\hline History & + & + & + \\
\hline Myth & + & + & + \\
\hline
\end{tabular}

Table 10 indicates the ways in which he perceives these forms being manipulated to achieve structural and behavioral change within a group.

\section{Table 10 \\ Some means of manipulating narratives to achieve change}

(Lincoln, B. 1989, p. 25)

1. Contest the authority or credibility of a given myth, reducing it to the status of history or legend and thereby deprive it of the capacity to continually reconstruct accustomed social forms.

2. Invest a history, legend, or fable with authority and credibility, thus elevating it to the status of myth and thereby make of it an instrument with which to construct novel social forms.

3. Advance novel lines of interpretation for an established myth or modify details in its narration and thereby change the nature of the sentiments (and the society) it evokes.

Given the extent to which diversity issues create relationship conflict, the significance of Lincoln's classification for College Students may rest in the predisposition of this group to rely heavily on peer interaction, relationship and reinforcement. (Fowler, 1986, Gilligan, 1982) A specific application may be in helping persons and cohorts to manipulate their stories and effect changes in cross cultural attitudes and behavior.

Another religious historian, Mircea Eliade, connects spirituality, myth and psychology in observing that 
When Jung entitled one of his books Modern Man in Search of a Soul, he implied that the modern world ... is in quest of a new myth, which alone could enable it to draw upon fresh spiritual resources and renew its creative powers. (p.25, 1957) 


\section{Methodology}

Implications of Literature Review for Methodology

Significant insights from the Literature Review which suggest themselves as resources in hypothesizing an effective methodology for assessing Spiritual Development include the following:

- Erikson, Piaget, Perry, Kohlberg, Fowler, McAdams, and Marcia have used qualitative methods. Their research used structured interviews, narrative and life story exclusively or in combination with more positivistic instruments. Qualitative methodology is both consistent with the tradition of research in student development and appropriate to the emerging paradigm.

- There is an apparent interweaving of Spiritual, Religious, Faith and Moral constructs along the warp and woof of Cognitive and Psychosocial Development. The tapestry created on this selfworked loom may be understood as Identity.

- Lifestory, myth, metaphor and other images are mediate to substance and meaning in and among these constructs.

- Community, connectedness and shared perception are significant to the concept of spirituality and to the experience of traditional aged students.

- Spirituality and Faith are interior human qualities more basic than the social phenomenon understood to be Religion or the cognitions understood as belief.

- The way in which students respond to the experience of their development may be significant. Rather than focusing on which developmental models may apply, the profession might legitimately ask "How and with what do individual students cope as their unique, personal self develops and unfolds?" 
If perception of and/or response to an experience involving relationship with self, other, nature or the Ultimate is understood to reflect or relate to spirituality, then the form and context in which such responses are communicated may enable its assessment (Schafranske and Gorusuch, 1984, Canda, 1986, Elkins, 1988)

Whether Spiritual, Faith, Religious or Moral awareness and development labels a given student's coping or experiential navigation system, life story and its symbolically imaged expressions including myth and metaphor are seen to play an important role in their orientation process. These images may provide more authentic and more authoritative windows through which to study these dynamics. (Foshay, 1984, Fowler, 1981, 1984, Mosley, Jarvis \& Fowler, 1986, McAdams, 1985, Rich \& DeVitis, 1985)

Life story and "Myth" can be seen as shapers of a person's life and as the ongoing collection of one's behaviors and experiences. It is a medium through which the perceptions, adjustments, and possibilities of one's life course (past, present and future) are transmitted. (Fienstein \& Krippner, 1989, Fowler, 1986, McAdams, 1988)

Kuh et al.'s projection of the emerging paradigm appears to be an accurate conceptualization of the context within which the proposed research would take place. Essentially, the Profession must study moving, chamelionlike subjects of which no two are alike excepting that all will go through significant and troubling developmental changes during their 
college experience. This suggests that more knowledge of all aspects of a student's development derived from an interactive, individualized, multi-functional assessment process will benefit the Profession.

If, from the student's perspective, he or she is to become more self developing in an increasingly more ambiguous setting, awareness and development of internal resources to aid in navigating the existential crisis(') inherent in development(s) is important. Becoming conscious of the role that Spirituality and related aspects of development have to play in life is also of value to the evolution of the whole student. (Fowler, 1981, 1984, Roth and McMahon, 1989, citing Kuh et al, 1987)

Descriptive, Naturalistic, Qualitative

Counseling Educator Joyce Conn suggests that the emerging study of spirituality will be

-descriptive and analytic

-interdisciplinary (including historical, psychological, literary and theological foci),

-ecumenical and cross-cultural

-inclusive and holistic

- participative

-designed to study concrete individuals as opposed to general classes or typical cases. (1989, p. 30)

Kuh and others (1986) indicate that a Naturalistic rather than Positivist approach to Student Development Research will be more appropriate to the emerging paradigm. 
Drawing largely on the work of Lincoln and Guba (1985) ${ }^{7}$, they enumerate the differences between positivistic and naturalistic research which are presented in Table 11.

\section{Table 11}

Axiomatic differences between Positivistic and Naturalistic Research

Lincoln and Guba, (1985) Positivistic

- single objective reality - observer independent of reality

- results generalizable - Iinear causation Naturalistic

-multiple realities - researcher and subject mutually shaping -ideographic/idiosyncratic -simultaneous \& mutual causation

Naturalistic inquiry is understood to be

interactive, synergistic, emergent inquiry that takes place in situ; that is, the natural setting of whatever is to be studied. A naturalistic research design or plan of study is emergent in that decisions about problem definitions and data collection (from whom, when, how) are not made a priori. (1986, p. 94)

Other characteristics of its "emergent" aspect include

- sampling strategies are modified as study unfolds

- there is an ongoing evaluation of data and method

- theory becomes grounded by data

and

Grounded theory also requires that data analysis be continuous, and occur at the same time as data collection. Theory is constructed from the researcher's interpretation of data, in the process of identifying patterns, relationships and meanings. ... [G] rounded theory ... [is] an evolutionary and never-ending expansion and refinement of understanding of the behavior or event under study. (1986, p. 96)

7 Lincoln and Guba, indicate that naturalistic "has other aliases as well, for example: the postpositivistic, ethnographic, phenomenological, subjective, case study, qualitative, hermeneutic, humanistic." (1985, p. 7) 
A set of criteria for a trustworthy naturalistic inquiry are presented and compared with their positivistic analogues. These are shown in Table 12 .

\section{Table 12}

Criteria for Trustworthiness in Naturalistic Inquiry Guba (1980)

\begin{tabular}{cc}
\hline Positivistic & Naturalistic \\
\hline internal validity & $\begin{array}{c}\text { credibility } \\
\text { (truth value of inquiry) }\end{array}$ \\
reliability & $\begin{array}{c}\text { transferability } \\
\text { (applicability) }\end{array}$ \\
objectivity & $\begin{array}{c}\text { dependability } \\
\text { (consistency) } \\
\text { confirmability } \\
\text { (neutrality) }\end{array}$ \\
\hline
\end{tabular}

In completing their discussion of Naturalistic inquiry in the higher education environment, Kuh et al., emphasize the value of

Hermeneutics, the science or art of interpretation ... [which] ... has been used to distill deeper, richer understandings from written works ... moving from general to specific and back, the scholar uses the information ... to capture a more informed sense of the contributions of the entire work ... [and the] ... more complicated relationships between the various parts of the whole. (1986, p.101 ff)

and they suggest that an example of holonomy in the emergent paradigm is their observation that

"[e] ach student is assumed to have information about the experience of all students". (1986, p. 102) 
Miles and Huberman in discussing Qualitative Assessment as research in use, point out that

the creation, testing and revision of simple, practical and effective analysis methods is the highest priority for qualitative researchers. (1984, p.21)

They go on to suggest a Data Analysis Model for Qualitative researchers which incorporates three interactive streams of activity. Figure 3 represents this model. It may be noted that the continuously interactive relationship among data reduction, display and conclusion drawing compliments the hermeneutic process espoused by kuh et al.

\section{Figure 3}

Components of Data Analysis: Interactive Mode: Miles \& Huberman (1984,p 23)

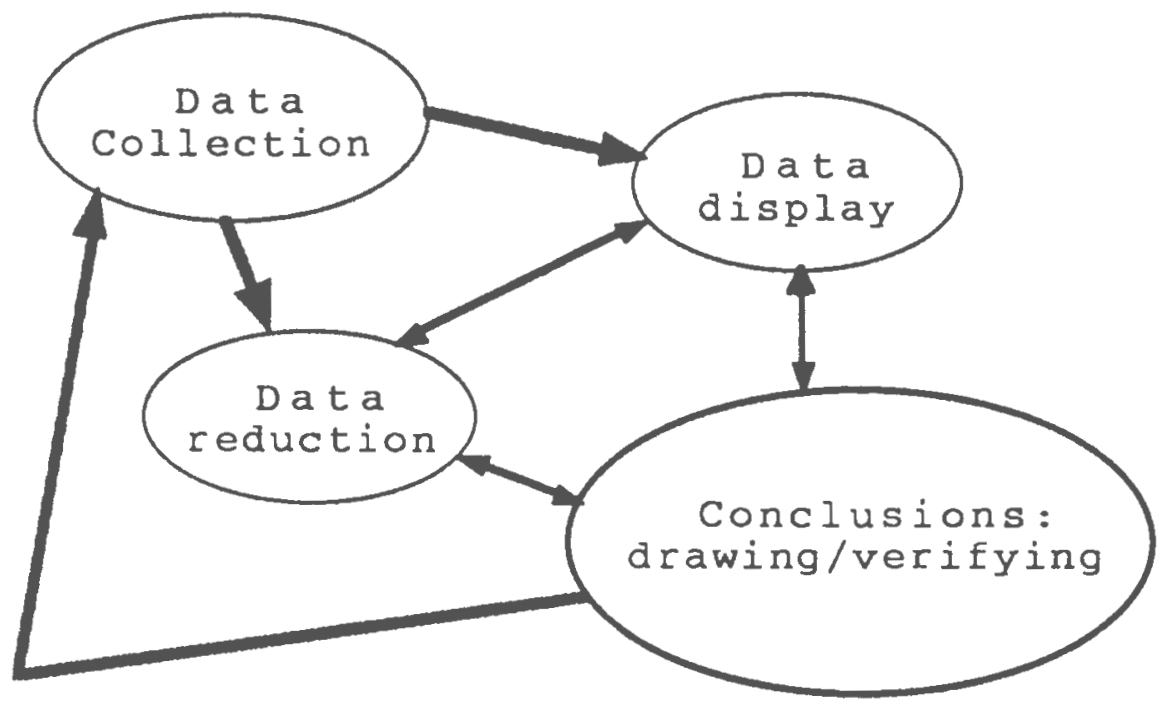


Table 13 presents the attributes of each stream.

\begin{tabular}{|c|c|}
\hline \multicolumn{2}{|c|}{$\begin{array}{c}\text { Table } 13 \\
\text { Qualitative Data Analysis Model } \\
\text { Miles \& Huberman (1984) }\end{array}$} \\
\hline Phase & Attributes \\
\hline - Data Reduction & $\begin{array}{l}\text { - selecting } \\
\text {-coding } \\
\text { - focusing } \\
\text { - simplifying } \\
\text {-abstracting } \\
\text { - transforming } \\
\end{array}$ \\
\hline - Data Display & $\begin{array}{l}\text { - iterative } \\
\text { - systematic } \\
\text { - clarifying } \\
\text { - suggestive } \\
\text { - disclosing }\end{array}$ \\
\hline - Conclusion Drawing/Verifying & $\begin{array}{l}\text { - meaning } \\
\text { - patterns } \\
\text { - regularities } \\
\text { - causal flows } \\
\text { - propositions } \\
\text { - testing }\end{array}$ \\
\hline
\end{tabular}

The research methodology envisioned by this thesis has been characterized as Qualitative. There are three identifiable stages embracing the present project. Each relates to the concept of "Qualitative" research somewhat differently. The stages are:

1. Evaluation of the existing resources

including the literature, the subjects and the researcher $(s)$.

2. Collection \& Analysis of data for the assembly of the "instrument".

3. Collection \& Analysis of data through administration of the "instrument".8

8 Not included in this thesis. 
If understood as a continuum of activities, these stages may be characterized as moving from mainly Descriptive through more Naturalistic to more traditionally Qualitative. It is projected that in the long term, the movement along that continuum will also represent a shift to progressively more quantitative activity in the Data Analysis streams.

\section{Myth and Metaphor: Data Collectors/Carriers}

Available descriptions and definitions of Myth include the following:

[Myths are] interlocking stories, rituals, rites, "customs and beliefs that give a pivotal sense of meaning and direction to a person, a family, a community or a culture ... myth is cultural DNA, the software, the unconscious information, the program that governs the way we see 'reality' and behave. (Keen, 1988)

and

[having] to do with the stages of life, the initiation ceremonies as you move from childhood to adult responsibilities ... (t) hey have to do with your recognition of the new role that you're in, the process of throwing off the old one and coming out in the new, and entering into a responsible profession. (Campbell \& Moyers, 1988, p. 12)

and

Myths are the instruments by which we continually struggle to make our experience intelligible to ourselves. A myth is a large, controlling image that gives philosophical meaning to the facts of ordinary life; that is which has organizing value for experience. A mythology is a more or less articulated body of such images, a pantheon. ...Myth is fundamental, the dramatic representation of our deepest instinctual life, of a primary awareness of man in the universe, capable of many configurations, upon which all particular opinions and attitudes depend. (Murray, 1968, p.355-56 quoted in Doty, 1986, p. 10)

and

Myths, in the sense that we are using the term, are not legends or falsehoods. They are, rather, the 
models by which human beings code and organize their perceptions, feelings, thoughts, and actions. Your personal mythology is rooted in the very ground of your being, and it is also a reflection of the mythology held by the culture in which you live. (Feinstein \& Krippner, 1988, p. 4)

and are

convey [ed] by means of ... metaphoric and symbolic diction, ... graphic imagery, and ... emotional conviction and participation...(Doty, 1986)

Given a conception of myth that includes symbols and collections of forms which serve as symbols, it is interesting to note that wilber theorizes that the ability of a person to think symbolically produces development or transformation from one level of consciousness to another. In this vein he adds that the capacity for thinking in terms of signs is related to translation within a given level. (Wilber, 1979)

Wilber's "within stage translation" suggests a resonance with Piaget's concept of "horizontal decalage" or "within stage development". Movement from position five to position six within Perry's Relativism Category would be an example of horizontal decalage. (King, 1978)

Social studies educator, Arthur Foshay, in an analysis of the descriptions of peak/spiritual experiences by theologians (Buber, Otto, Luther, Tillich) and psychologists (Kohlberg, B. Bloom, Maslow) describes symbolism's role in relation to the idea of spiritual:

The term "spiritual" includes the entire range of meanings in our time. It has shed none of the meanings it has ever had. The only new term associated with it is Otto's numinous, which "can 
only be induced, incited and aroused" (quoting otto, p.60, in Foshay 1984) or, in Maslow's language, "triggered". (Maslow, 1982, p.168)

... [B] oth the theologians and Maslow fail to conceptualize the spiritual/peak experience, though they all claim that the experience is real. The idea seems to exist in a cloud of meaning, not as a concept. It is a "state of mind", "purely felt experience, only to be indicated symbolically, by 'ideograms'" (quoting Otto, p.59, in Foshay, 1984)

In a cross sectional study, Hardcastle and others (1985) have compared metaphorical recollections of elementary and secondary school environments among American and Chinese college education majors. Significant differences were noted in the choice of "family" and "team" metaphors on a cultural basis. The researchers note that gains could be made by "exploring the metaphorical selections of school
drop-outs, experienced teachers and successful
professionals. .. the usefulness of metaphor and
imagery for human inquiry has been made evident in
the process of this study. The cultural contrast
in the selected metaphors for the recalled
elementary schools and the ideal secondary schools
led us to consider factors that would have been
overlooked otherwise. "in western civilization we
have valued concept at the expense of image, Abbs
tells us (1981, p 475 ), "and this has culminated in
an extraordinary alienation of man from the sources
of his own being." For teachers, this awareness
seems especially significant. When we are out of
touch with our own being, unconscious of our
orientations, and blind to the metaphors that guide
us, we may well stray from the human course, and
take our students with us. (p.314, 1985 ) Miles and Huberman (1984) have noted that making metaphors is a powerful data reduction technique for qualitative researchers. Metaphors are seen as pattern making devices, as decentering aides pushing researchers to more inferential and analytic perspectives and as "ways of connecting findings to theory". (p. 221) 
In Phase 1 of the Methodology proposed below, Metaphor plays the role of data reducer and decentering aide. Acknowledging the mutually shaping nature of the research experience for both the participants and the researcher, Phase 1 allows the participants to research themselves and their own experiences and requires them to reduce their data into metaphorical containers. The process presses both the researcher and the participants to decenter and seek a higher ground or perspective so that patterns and connections to theory may be discerned (the researcher) and meaning and expanded awareness may be explored (the subjects).

Gordon (1961) describes the use of evoked metaphor in small groups to solve the shared problem of developing creative solutions to organizational needs, new product design and social challenges. The school of Theology at The University of the South has used metaphor evoked in a small group seminar as an intermediate stage in a theological reflection process focusing on a critical incident in an individual group member's experience. (duBary, 1975, Brewer \& deBeers, 1986) The use of metaphor in individual therapy applying the principles espoused by Milton Erickson has been described by Lankton and Lankton, (1989) and Mills and Crowley, (1988). 


\section{The Proposed Methodology}

The present research, hypothesizes a means of assessing spirituality which would have the capacity to:

- identify the Myers Briggs Preferences involving Extraversion/Introversion, Intuition/Sensing and Thinking/Feeling of the student prior to obtaining a personal myth.

- using a "seed metaphor" evoke a personal myth from the subject which spans Erikson's Psychosocial Stages IV, V, VI and VII.

- obtain a quantitative index of the spiritual Orientation of the subject using Elkins' SOI after obtaining the personal myth.

- evaluate the personal myth utilizing analytic and hermeneutic tools and developmental templates applied in various disciplines.

The methodology, would develop in two Data Collection phases. In Phase 1, Metaphors, which may be understood as building blocks of myth, are evoked in small groups of students who share thoughts and feelings about a common experience. These metaphors are collected and evaluated, for their potential to stimulate or "seed" the growth of a "metaphoric or mythically" framed life story. Phase 1 is the focus of the present study.

In Phase 2, a "seed metaphor" will be administered to a larger group of students in a paper and pencil setting. These "seeds" would stimulate the growth of "metaphoric life story" or "personal myth" encompassing Stages IV, V, VI, \& VII of Erikson's Psychosocial development scheme. It is hypothesised that the (se) seed metaphor(s) will develop 
"metaphoric/mythic life story" in a manner which may be analogous to that in which a "seed crystal" initiates the growth of larger and more complex crystalline structures. It is conceivable that the seed metaphor's function will be more "organic" and resemble, for example, the way in which tomatoes grow. It is expected that the "personal myths" or "life stories" which develop will contain 'data' relating to the Spiritual, Faith, Moral, Identity and Ego Development of the individual subjects. Phase 2 Data are not presented in this thesis.

Unlike the manners in which Hardcastle, Gordon, The University of the South or the Lanktons developed and applied metaphor, the present research "collects" the "seed metaphor(s)" from a small sample of potential subjects who are focusing on a common though not necessarily concurrent "experience". The protocol for Phase 1 is presented in Table 14 below. 


\section{Table 14}

Phase 1 Data Collection:

Develop "seed" Metaphor

Small Group $(n=6-10)$

\begin{tabular}{|c|c|}
\hline Steps & Comments \\
\hline $\begin{array}{l}\text { - Administer Myers-Briggs } \\
\text { Inventory (MBTI). }\end{array}$ & $\begin{array}{l}\text { - Abbreviated form. } \\
\text { Participants do not score. }\end{array}$ \\
\hline $\begin{array}{l}\text { - Conduct guided imagery on } \\
\text { the common experience of } \\
\text { starting college. }\end{array}$ & - \\
\hline - Group Reflection & $\begin{array}{l}\text { - Participants enumerate } \\
\text { thoughts and feelings about } \\
\text { the experience. } \\
\text {-Arrive at a 'consensus } \\
\text { cluster' (CC) of thoughts and } \\
\text { feelings which all agree were } \\
\text { present to their experience. } \\
\text {-Evoke metaphors which } \\
\text { participants feel contain the } \\
\text { CC. } \\
\text {-Establish Consensus } \\
\text { Metaphor. All must agree. } \\
\text { - Enumerate thoughts, } \\
\text { feelings, impressions, } \\
\text { evaluations and reflections } \\
\text { of what it is like "Inside. } \\
\text { the Metaphor". }\end{array}$ \\
\hline $\begin{array}{l}\text {-Administer Elkins' Spiritual } \\
\text { Orientation Inventory. (SOI) }\end{array}$ & $\begin{array}{l}\text { - } 85 \text { question, paper \& pencil, } \\
\text { Likert scale, trait factor } \\
\text { instrument. }\end{array}$ \\
\hline
\end{tabular}

Administration of the MBTI will enable efforts to evaluate and/or account for the inter and intrapersonal energy dynamics (Extraversion versus Introversion), information gathering styles (Intuitive versus Sensing) and data processing and decision making styles (Thinking versus Feeling) of the groups developing 'seed metaphors'.

The use of the MBTI provides a test of the possible correlation between personality/temperament disposition and a construct describing preferred paths to spiritual awareness and development. 
The SOI will also be used to compare Means for the entire class. Each seed metaphor generating session's Means for the SOI will be compared with the Means for the entire class. Given Elkins' report of age related increases in subscale scores, this quantitative "Fence" may be useful in evaluating session participation and output with regard to demographic makeup. (Elkins, 1988)

\section{Guided Imagery}

The use of Guided Imagery as an evocative process for creative and educational activity is reported by cottrell (1983), Galyean (1981) and North-Shea (1979) among others. Cottrell's work suggests it as preparation for stage performers as a means of engaging their roles. She reports that during their debriefing participants

relate [their] metaphoric adventure to those of the writer or writers whose work [they] are exploring as [they] ... seek just the right words to recreate ... experiences for others. (p. 6, 1983)

In the context of a discussion of transpersonal education Galyean (1981) suggests that imagery activities can be "a direct means for students to work with their 'higher selves"" (p.62) and "promise to be effective agents of physical, emotional, intellectual, and spiritual growth in education settings". (p.66)

North-Shea (1979) conducted a study among fifty male prison inmates in which guided fantasy was used as a vehicle for stimulating metaphoric activity and relating this "source of viable, living myth" with the elements of current 
"cultural myth" that the inmates need in some way to reframe for themselves in a positive manner. Pre and post testing with the Tennessee Self Concept Scale suggests significant change in three aspects of self concept.

The guided image applied in Phase 1 is designed to replicate the sort of quest or hero cycle suggested by Campbell. (1968) The present research hypothesizes this as archetypal to Erikson's Stage IV. Table 15 relates the cycle of the Guided Image to Campbell's scheme.

\section{Table 15}

Hero Cycle: Guided Image/Myth Template Campbell (p. 245, 1968)

\begin{tabular}{|c|c|}
\hline $\begin{array}{l}\text { Hero Stage } \\
\quad \text { Guided Image }\end{array}$ & Characters/Events \\
\hline $\begin{array}{l}\text { Call to adventure } \\
\text { Anticipates and } \\
\text { Decides to enter } \\
\text { College }\end{array}$ & $\begin{array}{l}\text { Lured, carried away or voluntarily } \\
\text { moves to threshold of adventure }\end{array}$ \\
\hline $\begin{array}{l}\text { Threshold crossing } \\
\text { Arrives at college }\end{array}$ & $\begin{array}{l}\text { Encounter with guard, engages and } \\
\text { defeats, conciliates or is defeated } \\
\text { and crosses into world of unfamiliar } \\
\text { yet strangely intimate forces, some } \\
\text { of which ... test ... help ... } \\
\text { [dragon-battle, crucifixion, } \\
\text { abduction, wonder journey, whale's } \\
\text { belly] }\end{array}$ \\
\hline $\begin{array}{l}\text { Undergoes supreme Test } \\
\begin{array}{r}\text { Moves bevond first } \\
\frac{\text { davs of arrival to }}{\text { involvement with }} \\
\text { college }\end{array}\end{array}$ & $\begin{array}{l}\text { Sacred marriage } \\
\text { Father atonement } \\
\text { Self-divinization } \\
\text { Boon-theft }\end{array}$ \\
\hline $\begin{array}{l}\text { Return } \\
\text { Recalls first Return } \\
\text { Home whether real or } \\
\text { imagined. }\end{array}$ & $\begin{array}{l}\text { Leave transcendental powers (helpers) } \\
\text { behind } \\
\text { Reemerges from kingdom of dread } \\
\text { Resurrection } \\
\text { Rescue } \\
\text { Threshold Struggle } \\
\text { The boon or elixir carried back } \\
\text { restores the world }\end{array}$ \\
\hline
\end{tabular}


Unlike many applications of guided images, there is no effort to engage the participant in decision making or sidetrips during the image period. The objective is to condition participants to affective and cognitive recall of a Temporal experience and for later activity at the connotative/aesthetic levels in the Intuitive regions of the Height of Consciousness. Within the Guided Image, the participants are essentially asked to "read" their life stories from the vantagepoint of the interface between the Temporal Sector (Memory) and Depth of Consciousness (Fantasy). (von Eckartsberg, 1981)

A view of the metaphor development steps in Phase 1 and how the process relates to von Eckartsberg's Psychocosm is shown in Figure 4, below. Terms used in Figure 4 can be found in the Working Definitions section, page 69. 


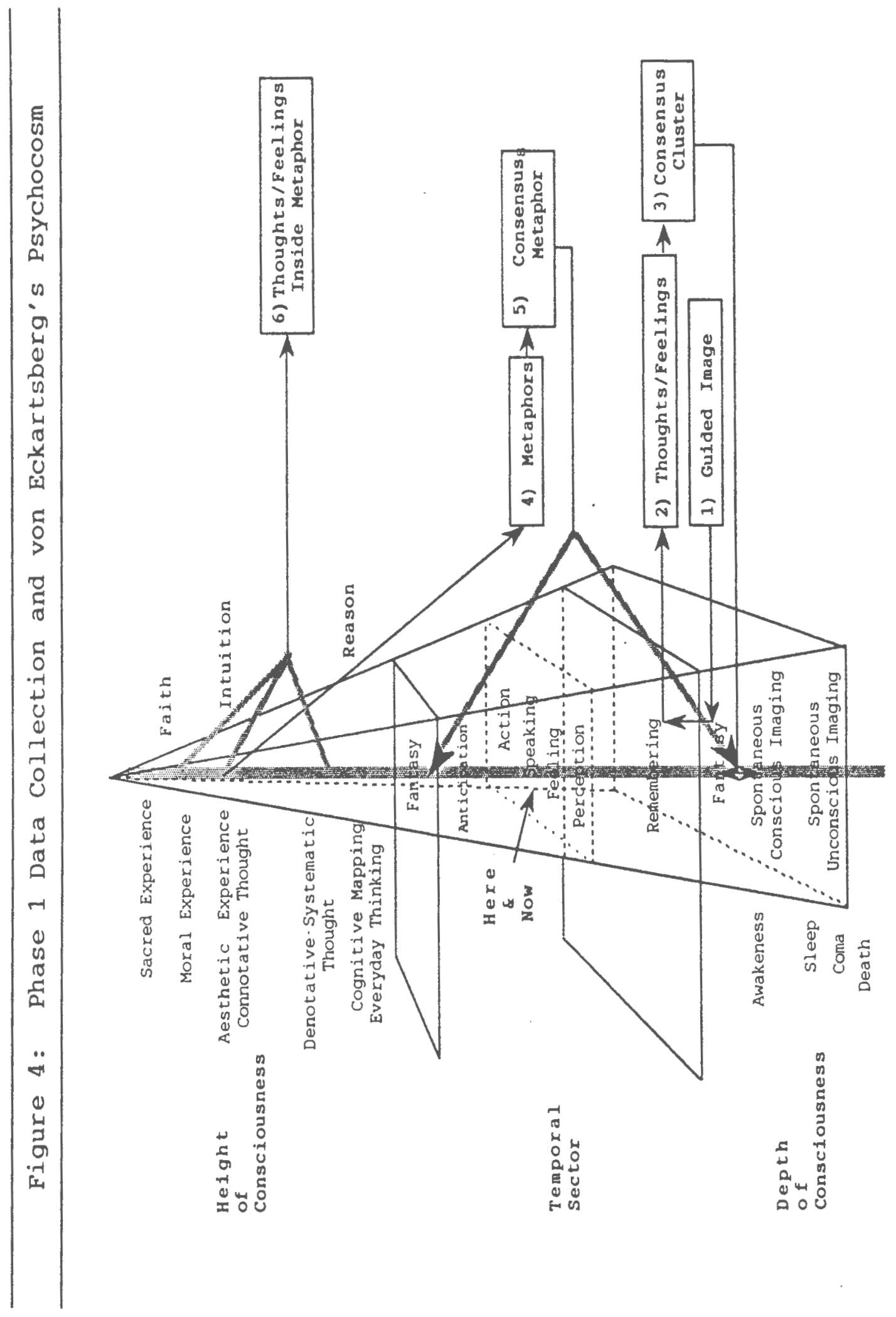




\section{Working Definitions}

In hypothesizing the assessment of spirituality through myth and metaphor a working definition of spirituality and of the elements of the assessment methodology have been developed.

The working definition of spirituality which guides the present research agrees with much of both Canda's and Elkins' models. It is felt that the attribution of a "gestalt" in the case of Canda's definition and the requirement for "awareness" of a transcendent dimension as described by Elkins may be best left to future consideration. Life as represented in Elkins is understood to be a value instead of a subject/object of relationship. This working definition and its schematic representation relative to its assessment through Myth and Metaphor follows. (Figure 5)

Spirituality is a person's way of being in and experiencing relationship with and through self, others, nature and the Ultimate. It is a qualitative aspect of behavior. The person's behaviors and responses are characterized by identifiable values regarding each.

With a widely based view of life story represented in metaphor and myth and an appreciation of its impact upon groups and individuals, it is possible to suggest preliminary working definitions of myth, metaphor and other key terms involved in the present research. 


\section{Figure 5}

Working Definition of Spirituality

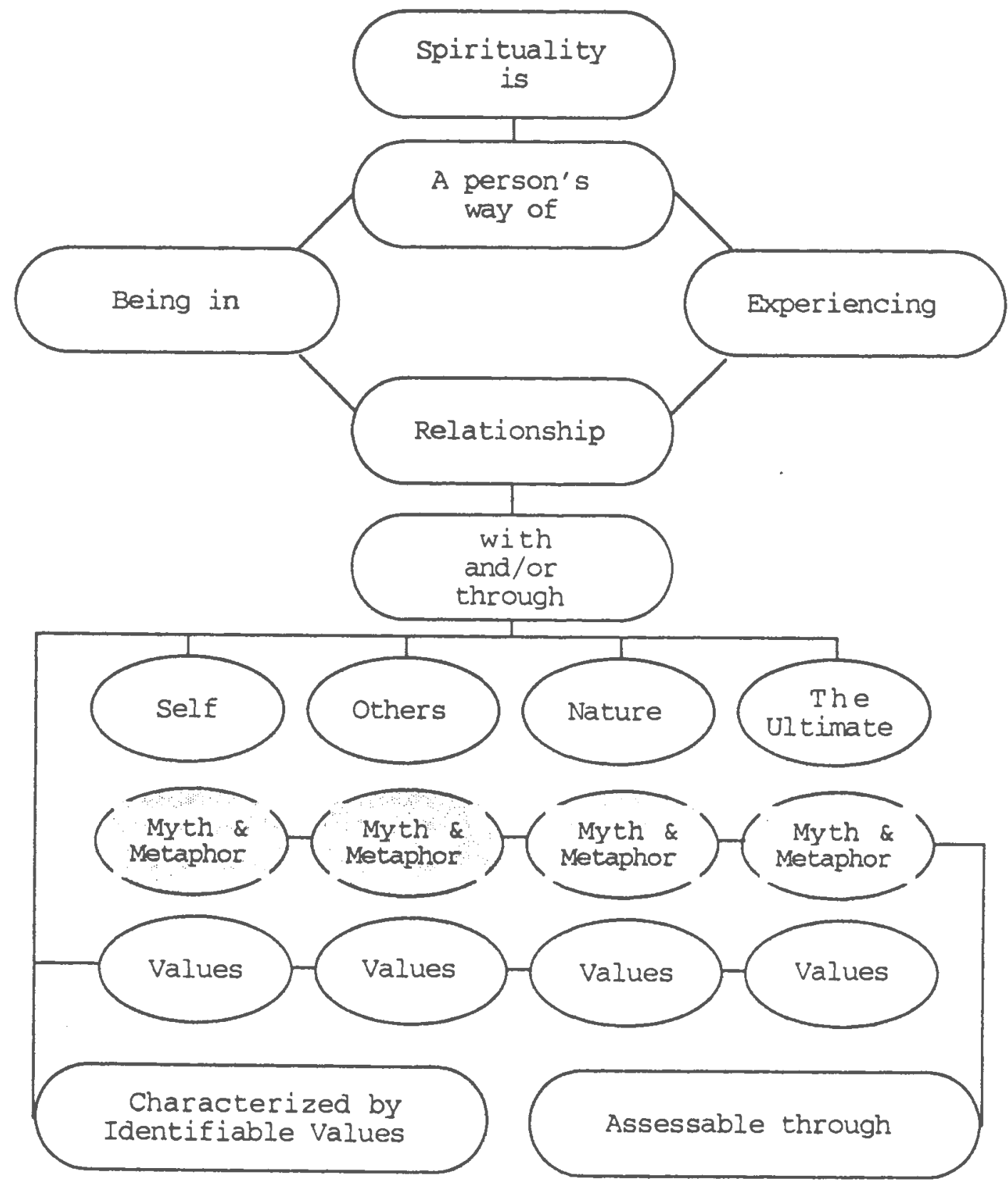


A Myth is a coherent collection of evocative images in narrative form which represents a meaningful individual and shared perception of experienced reality involving relationship with self, other(s) and/or environments and which in repeated recollections is credible and authoritative. (eg.) The Story of the Life of Arthur and the Knights of the Round Table.

A Symbol is a meaningful verbal or visual image of an object, an action or an experience that represents another or others by implied association or resemblance. (eg.) The Round Table.

A Sign is a specific symbol whose meaning is restricted by convention to the representation of an explicitly designated subject, object or fact. (eg.) To others, Uther Pendragon's Shield (a dragon).

A Metaphor is a symbol which carries the meaning(s) of a symbolic expression it ordinarily represents to one or more expressions that it may designate by comparison; it is a connotative carrier of the cognitive and emotional meaning evoked by perception of an experience. (eg.) The attempt to remove the Sword, Excalibur from the stone.

A Seed Metaphor is a metaphor elicited in Phase 1 from a small group of individuals who have shared a common, though not necessarily concurrent experience. It is the group's consensus that the metaphor contains the thoughts and feelings that are associated with the shared experience. A 
Consensus Metaphor is identical in its derivation, though not necessarily appropriate for use as a "seed".

A Principal Metaphor is one which a simple majority of Phase 1 participants believe contains the thoughts and feelings that are associated with the shared experience.

A Consensus Cluster is the group of thoughts and feelings within a given Phase 1 session which all participants agree are part of the experience upon which the group is focusing.

Inside the Metaphor refers to the thoughts, feelings and other verbal observations and perceptions made by Phase 1 participants reflecting on life inside the Consensus Metaphor. 


\section{Findings}

\section{Phase 1 Results and Analysis}

Students in an undergraduate course in Personal

Development (HCF150) at The University of Rhode Island participated in the research as a part of their classwork. The Phase 1 Data Collection procedure described in Table 14 was conducted during finals week of the Fall Semester, 1989. Participation was required to complete the student's semester grade. Participation was the only stipulation regarding the grade. The quality or content of an individual's participation was not considered in the grading and this stipulation was made clear to the entire class.

\section{Demographics}

Of forty-one students enrolled in the course, 39 participated. The researcher facilitated or co-facilitated four of the five groups with the course instructor. Table 16 describes each group in terms of demographics, the MBTI and SOI. 


\section{Table 16}

Demographic, MBTI and SOI Profile of Phase 1 Groups

M3 $\quad \underline{\text { T3 }} \quad \underline{\text { W4 }} \quad \underline{\text { R4 }} \quad \underline{\text { F2 }}$

$n=7$

$\mathrm{n}=8$

$\mathrm{n}=8$

$\mathrm{n}=8$

$n=8$

Leaders Leaders Leaders Leaders Leaders

$\begin{array}{ccccc}2 & 1 & 2 & 1 & 2 \\ \text { der } & (8) \text { Gender } & (8) & \text { Gender } & (8) \\ \text { Gender } & (8) & \text { Gender }(8)\end{array}$

Gender (8) Gender (8) $\frac{\text { Gender (8) }}{F=6,(85.7)} \frac{\text { Gender }(8)}{F=6,(75.0)} \frac{\text { Gender (8) }}{F=7,(87.5)}$ $M=1,(14.3) \quad M=2,(25.0) \quad M=1,(12.5) \quad M=2,(25.0) \quad M=2,(25.0)$

\begin{tabular}{cllll} 
Class & Class & Class & Class & Class \\
\hline Fr $=5$ & Fr $=1$ & Fr $=2$ & Fr $=1$ & Sr $=2$ \\
So $=2$ & $\mathrm{So}=2$ & $\mathrm{So}=1$ & $\mathrm{So}=4$ & $\mathrm{So}=1$ \\
$\mathrm{Jr}=-$ & $\mathrm{Jr}=2$ & $\mathrm{Jr}=2$ & $\mathrm{Jr}=1$ & $\mathrm{Jr}=2$ \\
$\mathrm{Sr}=-$ & $\mathrm{Sr}=3$ & $\mathrm{Sr}=2$ & $\mathrm{Sr}=2$ & $\mathrm{Sr}=3$
\end{tabular}
$\mathrm{O}^{\mathrm{a}}=1$

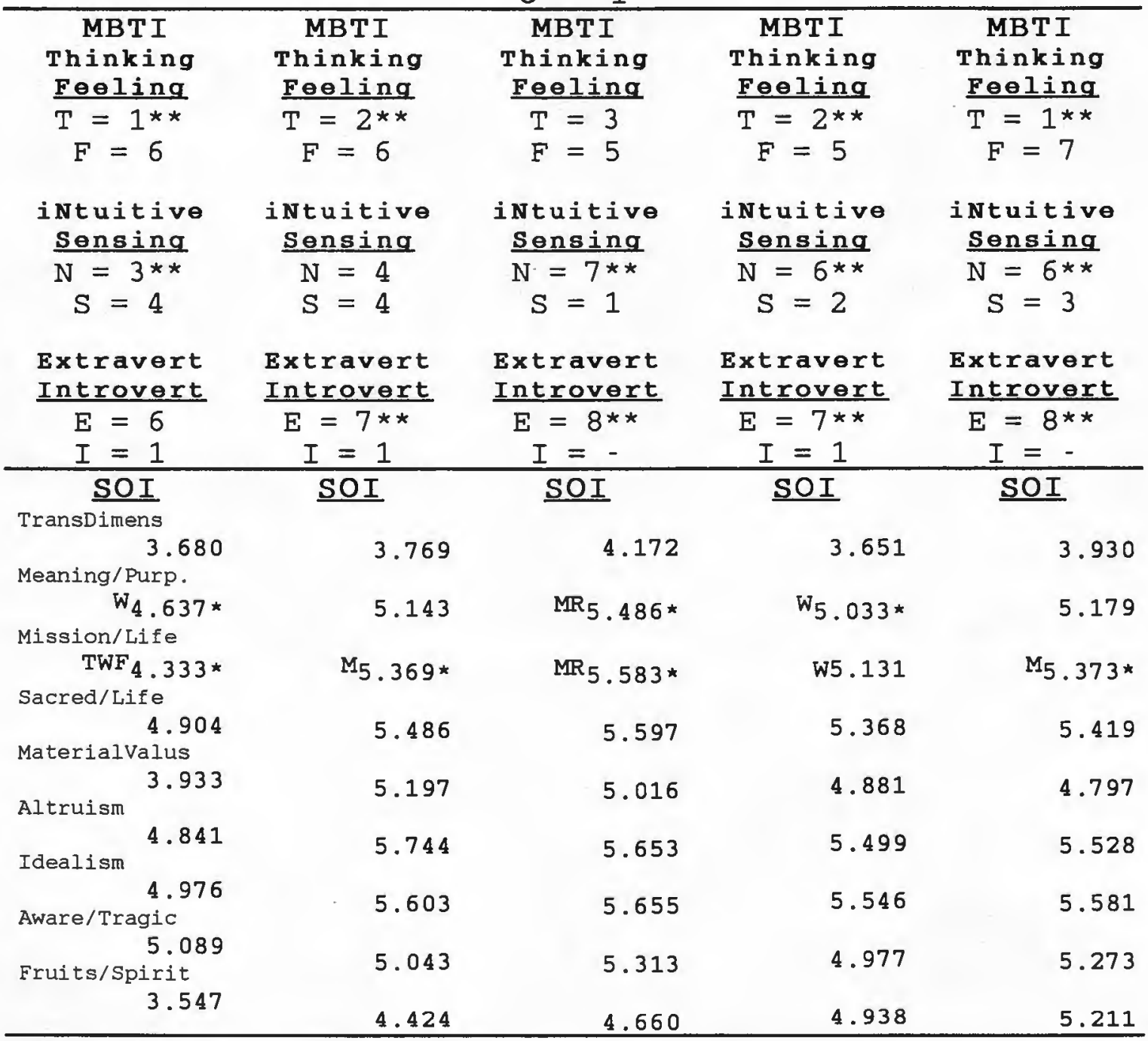

$0^{a}=$ non-matriculating.

${ }^{*} \underline{p}<.05$, two tailed, $* * \underline{p}<.01$, two tailed.

NOTE. $M 3=$ Monday, $3 \mathrm{pm} ; \mathrm{T} 3=\mathrm{T}$ uesday, $3 \mathrm{pm} ; \mathrm{W} 4=$ Wednesday, $4 \mathrm{pm}$;

R4 =Thursday, $4 \mathrm{pm} ; \quad$ F2=Friday, $2 \mathrm{pm}$. 
Each group numbered 7 or 8 undergraduates of traditional college age. Women represented between 75 and 87.5 percent of each group. M3 included Freshpersons (71\%) and Sophomores (29\%) and was the most homogeneous from a class status standpoint. All other groups had at least one representative from each class. Sophomores represented $50 \%$ of the participants in $\mathrm{R} 4$.

\section{Myers Brigas Temperament Indicator}

Since the Phase 1 process involves the capacity to express thoughts and feelings about an experience, the mix of cognitive and affective data processing preferences in each group relative to the norm in the Class of 1992 was noted. In all but session $W 3$, a test of proportions ${ }^{9}$ indicated that the groups varied significantly higher on the Feeling dimension than the $65.2 \%$ norm for the Class of 1992.

In terms of the preferred manner in which information is obtained, the Class of 1992 showed a fairly equal disposition between iNtuition and sensing. Varying significantly above the 52.5\% preference for $\mathrm{N}$ were groups $\mathrm{W} 4, \mathrm{R} 4$ and $\mathrm{F} 2$. Only M3 favored Sensing, while T3 conformed to the norm. Given the locus of Intuitive activity (Height of Consciousness) to that of the more immediate aspects of Sensing (Temporal Sector) hypothesized by von Eckartsberg (1981), this variance may warrant consideration in assessing the quality and quantity of Metaphor production in the Phase 1 process.

\footnotetext{
9 Bruning, J. L. \& Kintz, B. L. (1968), Glenview, IL: Scott,
} Foresman and Company. (p. 199) 
Of interest to the evaluation of both Thinking/Feeling and iNtuitive/Sensing dichotomies is the observation of Pollio and others (1977) who note that there is much speculation with regard to the relationship between cognitive style, the preference for metaphoric language and the capacity to produce novel metaphor. (J. E. Knott, Personal Communication, March 31, 1990)

In the direction of Extraversion, groups T3 through F2 varied considerably higher $(p<.01)$ and $M 3$ was very close to significance at the $p<.05$ level. To the extent that group process depends on energetic interaction among participants, this significant difference is assumed to be helpful. The absence of any Introverts in groups $W 3$ and F2 may have relevance for the more reflective portions of the process including the Inside the Metaphor step.

\section{Elkins' Spiritual orientation Inventory}

Recalling that the SOI is has yet to be normed, one way ANOVAS were performed comparing each session's means for each subscale with the means of every other session. Significant differences ( $p<.05)$ were found for the Meaning and Purpose scale between sessions $M 3$ and $W 4$ and between W4 and R4. The Mission in Life Subscale differed significantly between M3 and $\mathrm{T} 3$ and between $\mathrm{W} 4$ and $\mathrm{F} 2$. W4 also differed from R4 on this scale.

It may be that the age and inexperience of the lower division group in M3 is related to the lower levels of active commitment suggested by these findings. The fairly balanced 
mix of thinking and feeling types in w4 may account for its significantly higher scores on these subscales.

Sampling and Process Bias

As convenience samples, the groups presented several possibilities for bias. The fact that the students are enrolled in a Personal Development course and that the experience counted toward final grades could account for a portion of an individual's motivation and willingness to participate. In addition, with the Professor facilitating or co-facilitating all but one group (T3), the participants' level of comfort and familiarity with him could have influenced their participation and responses. However, reference to the group activity profile in Table 17 does not suggest any unusual difference for $\mathrm{T} 3$ in the Thoughts/Feelings or Metaphor steps.

As indicated in Table 14 above, Thoughts/Feelings are brainstormed by participants and used to generate a group of Metaphors containing the experiential content of their. arrival at college. A Consensus Metaphor is chosen and the students reflect on life Inside the Metaphor.

The relatively low input for T3's Inside the Metaphor stage is similar to R4 which was facilitated by the Professor alone. The principal activity difference between T3 and R4 involves time. T3 took 45 minutes longer to complete. It should be noted that the process apparently became more 
efficient as the week progressed with elapsed times declining from two and one-half to one and one-half hours.

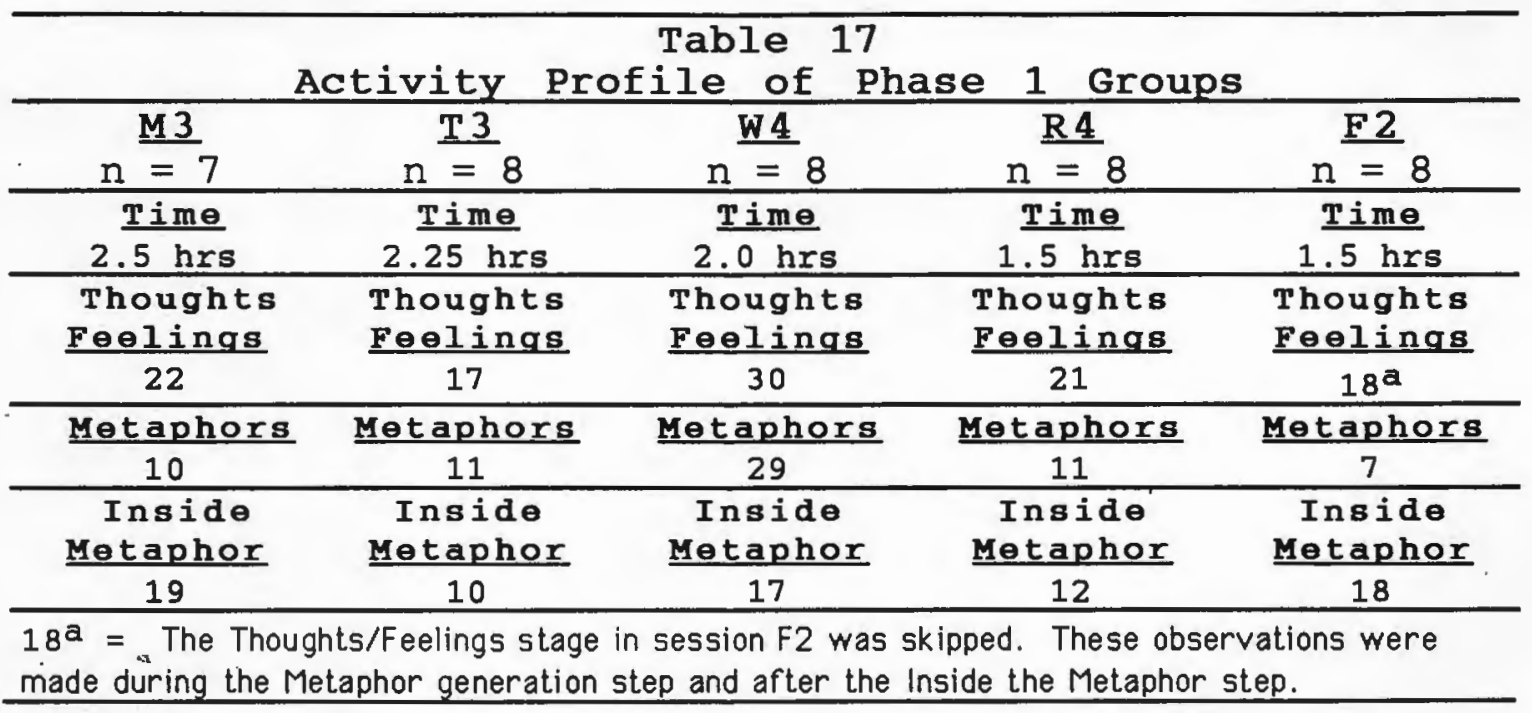

The potential of a sensitizing effect created by the course content and process has been considered. The HCF 150 student spends much time throughout the semester in introspective exercise and small group activity. It has been noteded by several professors and instructors that "growth" is observed through the semester.

Each of the five groups had unique aspects in its evolution of the process. Most notable in terms of differences was the effort in F2 to go directly to Metaphors from the Guided Image. This will be discussed in more detail below. In general, the remaining major components in the process remained the same except for the time at which the food arrived and the times at which individuals introduced themselves to each other with short biographical comments. Given the higher percentage of women participating, the possibility of gender differences would seem to exist. The 
male participation rate for each step in each group was noted. (Appendices A to E) A Test of Proportions relating the proportion of male participants to male contributions at each step in each group suggest a significant difference in the three groups in which Principal Metaphors were proposed by Males. In each of these groups (M3, W4 and F2) these Principal Metaphors were chosen as the Consensus Metaphors. ( $p<.01,2$ tailed) Across all five groups, Males proposed a total of 4 of the 19 Principal Metaphors.

The issue of Gender dominance in group participation and in Higher Education class settings has been of interest to researchers as recently as April 11, 1990. In a New York Times wire service story, the The Providence Journal reports a study conducted at Wheaton College by Harvard Educator Catherine Krupnick.

Detailed analysis of videotapes of Wheaton classes showed that, in a class where they made up onetenth of the students, male students would do a quarter of the speaking. They also tended to be more impulsive....

Krupnick said female students, by contrast, tended to want time to think about a question before offering an answer, and when they did respond, they were more likely than men to "enlarge on the ideas of a previous speaker rather than to challenge his or her initial assumption". (quoting Krupnick, Researcher reports ...p. A-9, 1990)

Other observations made during the study of classes at the small New England liberal arts college which has been coed for just two years include the fact that "professors are more likely to remember men's names, call on them in class 
and listen attentively to their answers. By contrast, they feel [more free] to interrupt women and ask them 'lowerorder' questions". (quoting Krupnick, Researcher reports (..p. A-9, 1990)

Another possibility suggested by the apparently related finding of the present research is that of a diversity or minority effect as opposed to solely a gender factor. That is, the significant variances obtained may be the predictable effect whenever a minority is accommodated to a group by a majority.

\section{Within Groups: Process Review}

The focus of each session was the sharing of the cognitive and affective content of each student's experience of beginning college. The objective of the process was to evoke a metaphor containing this shared perception. All sessions were recorded on audiotape. It should be noted that Participant contributions to each step were recorded on newsprint and taped to walls for reference throughout the session.

Participants were encouraged to assume a relaxed posture or to sit or stretch out on the carpeted floors. In all sessions, once the unscored MBTI's were collected, the Guided Image was initiated with reduced lighting in the room.

In analyzing the Data, each session has been reviewed a minimum of three times. The content of each session has been abstracted in Appendices A to E. 
It became clear in Session M3 that an immediate accommodation to the needs of transfer and commuter students was appropriate. For each group, therefore, it became routine to invite transfer students to substitute their experience at their first school as the subject of their reflection. For Commuters, beginning their first class or attendance at orientation was suggested.

Sessions M3, T3, W4, and R4 were marked by no substantive variance in the sequence of steps as indicated below:

1) Guided Image

2) Explore Thoughts and Feelings

3) Establish Consensus Cluster

4) Generate Metaphors

5) Select Principal Metaphors

6) Determine Consensus Metaphor

7) Explore Inside the Metaphor

In the case of $F 2$, steps 2 and 3 were eliminated. It is interesting to note that in preparing Appendix E, the words listed under "Content Cluster" were interspersed with Metaphors during the Metaphor Making step. Also unique to the process in F2 is that after exploring Inside the Metaphor for a considerable period, participants were asked to leave the Metaphor and to return to the 'beginning college' experience. Ensuing participant observations from that point 
are listed in the Thoughts and Feelings column for consistency in data display.

A less significant difference in procedure occurred in T3. During the brainstorming for Thoughts/Feelings, the researcher attempted to record Thoughts and Feelings separately on a newsprint "T" chart. Review of the audio recording indicates that the participants had considerable difficulty assigning their observations to one or the other column. Prompting by the facilitator produced some resolution, though for the balance of the steps in $\mathrm{T} 3$ and the remaining sessions, the effort to have Participants discriminate Cognitive from Affective material was dropped.

Of interest and impact to the Thoughts/Feelings step in Session w4 was the facilitator comment after a participant contributed "awe". The group was reminded that there was no rush, that periods of silence were fine and that the group would proceed to the next step only after everyone was comfortable that enough material had been recorded on the newsprint. As the Thoughts/Feelings column in Appendix C indicates, another 12 contributions followed including four which became part of the Consensus Cluster.

Approaches used to arrive at both the Consensus cluster and Consensus Metaphor varied in some details. In all cases $100 \%$ of the participants had to agree. In some sessions the list of contributions on the newsprint was reviewed systematically from top to bottom. In others, a long list was reduced to a shorter list and then further condensed 
while in yet another case the list was approached at random with participants determining the contribution to be addressed.

\section{Across Groups Data Analysis}

\section{Thoughts and Feelings}

Table 18 displays the Consensus Clusters of thoughts and feelings for each session. Rows A through $F$ of this table display six categories of words the researcher considered to be identical or very similar in content or meaning.

Row A lists some form of the word 'excitement' in 4 of 5 or $80 \%$ of the groups. These words suggest a fairly exterior locus of stimulation. The word 'psyched' (as are others in italics) is considered a likely though ambiguous member of that category.

Row B notes some form of the word 'free' or 'independent' in 3 of 5 or $60 \%$ of the groups. When the ambiguous 'no help' is added to this row, $80 \%$ of the sessions show inclusion of the concept of self reliance.

Eighty percent of the groups in Row C display words connoting positive present or future oriented feelings and are understood by the researcher to be more or less interior in their locus of stimulation. Among these are relatively passive or reactive words such as 'happy','secure' and 'relief' as well as more active notions such as 'eager, 'determined' and 'curiosity'. 


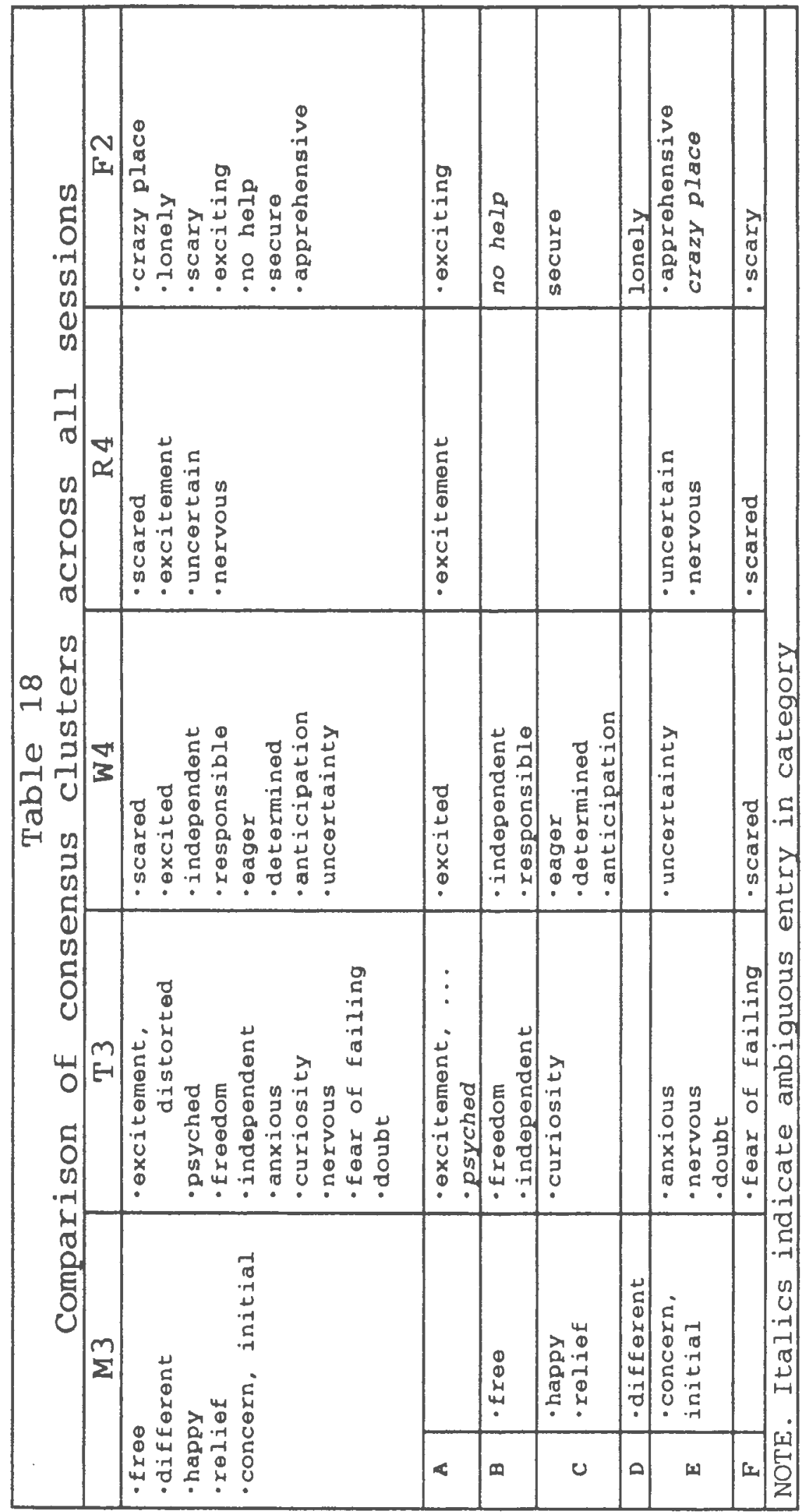


The least populated category (Row D) includes 'different' and 'lonely', words indicating isolation and uniqueness. This is interesting given the perception of the traditonal age college student's concern for relationship and concern with peer issues.

Every group produced at least one word expressing a moderate level of emotional discomfort judged to be internally stimulated. Row E displays these words which include 'concern', 'doubt', 'uncertain' and 'nervous'.

Finally, Row F indicates a category included in $80 \%$ of the groups. 'Fear' and some form of 'Scared' describe a fairly strong feeling understood to be associated with an external threat. In the case of 'fear of failing' (T3) it might be argued that the source of the threat may be interior.

Creating aids to the analysis of this kind of data should enrich an understanding of Content clusters. Willis and Allen (1974) created a ranked list of 38 adjectives to be used in assessing college student reaction to a course of study. The words were ranked as to their relative strength regarding depression versus elation and uninvolvement versus involvement. Words from Content clusters present on the Willis and Allen listing and their relative strengths include those in Table 19 below. 
Table 19

Phase 1 Data Adjectives:Involvement \& Elation Ratings Willis \& Allen (1974)

\begin{tabular}{lcc}
\hline \multicolumn{1}{c}{ Adiective } & Involvement & Elation \\
Rating & Rating & 6 \\
anticip(atory) & $\frac{8}{2}$ & 2 \\
concern(ed) & 7 & 4 \\
excited & 6 & 8 \\
lonely & 8 & 1 \\
\hline NOTE. the ratings are on a scale of 1 to 10 with 5 being \\
neutral
\end{tabular}

In looking at the content Clusters from the standpoint of what is not contained in them, it is interesting to note that M3 contains neither the notion of 'excitement' nor of 'fear'. It will be recalled that M3 is the most homogeneous and least experienced group from a class status standpoint. Looking at R4's negative space in Table 18 discloses that the ideas of 'independent' 'eager' and 'different' are not contained in this Cluster. A more heterogeneous group with $50 \%$ of its members Sophomores, neither R4's other demographics nor its MBTI or SOI indicators suggest anything which might account for this difference in Consensus Cluster content.

From the standpoint of patterns of inclusion, sessions T3, W4 and F2 present remarkable consistency. This is especially interesting since F2's process, as noted above represented a significant departure from that used in all others.

With regard to Across Groups Analysis of Content Clusters, it would seem to be accurate to suggest that the Thoughts and Feelings step exhibits the properties Guba 
(cited in Kuh et al., 1986) would characterize as credibility (truth value), dependability (consistency) and confirmability (neutrality).

\section{Metaphor Making}

The results of the steps involved in Generating Metaphors, Identifying Principal Metaphors and choosing a Consensus Metaphor are represented in Appendices $A$ to $E$ and Tables 20 and 21 .

A review of the entire Metaphor step in each session suggests that w4 was a particularly productive group with 29 metaphors generated.

Beyond the possible gender factor involving selection of Consensus Metaphors offered by males cited above, there do not seem to be other differences of a quantitative nature.

The possibility of an order effect influencing the initial selection of Consensus Metaphors has been considered with none observed. However, once Principal Metaphors were selected, the possibility of an order effect became apparent. Reference to Table 20 indicates the Consensus Metaphors in bold face type. In M3, T3, and F2, the last Principal Metaphor became the Consensus Metaphor. In the Case of W4, it may be argued that the thematic character of the Consensus Metaphor (Starting new job) was sufficiently close to the last Principal Metaphor offered to suggest some sort of transfer. 


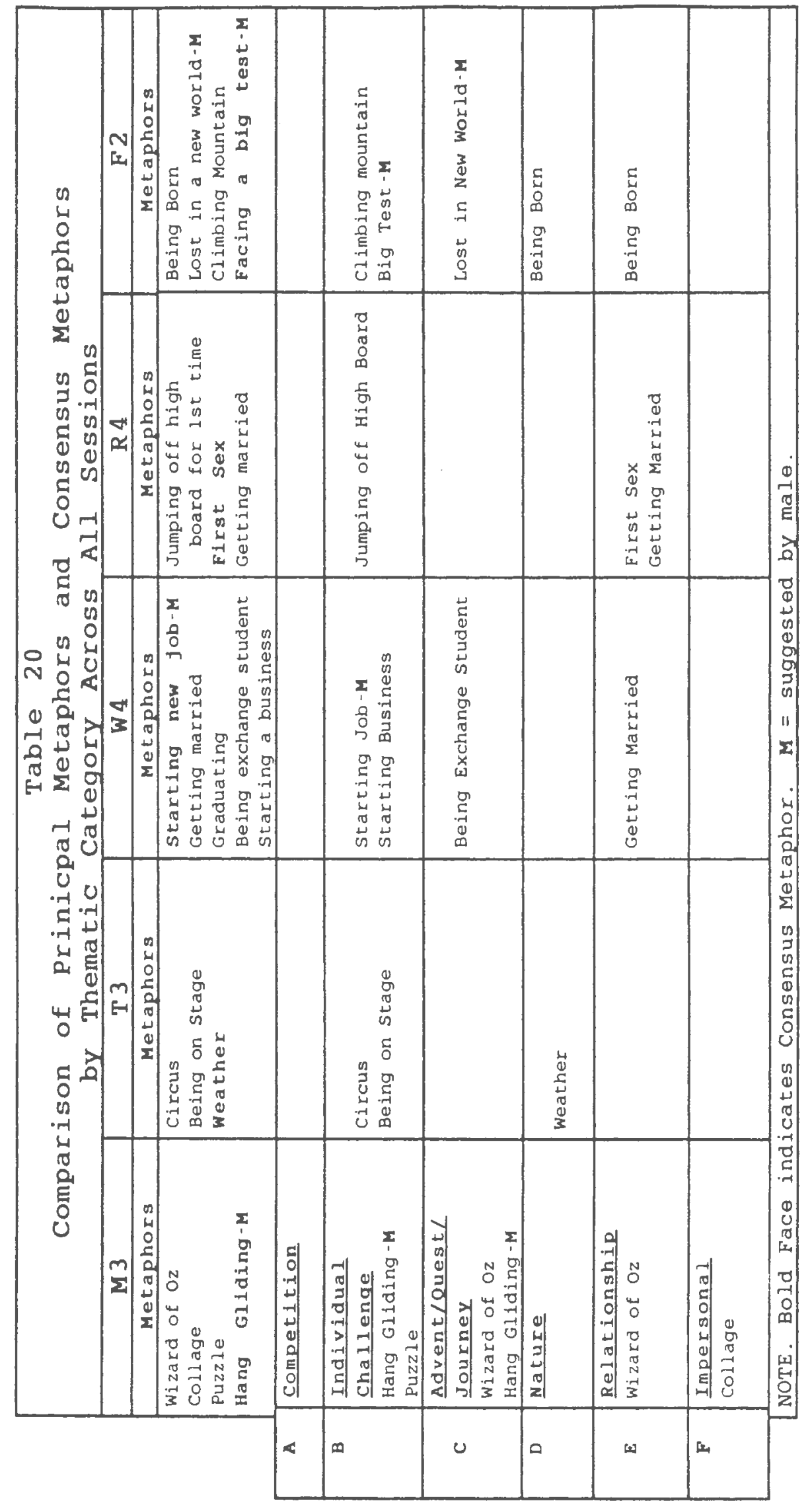




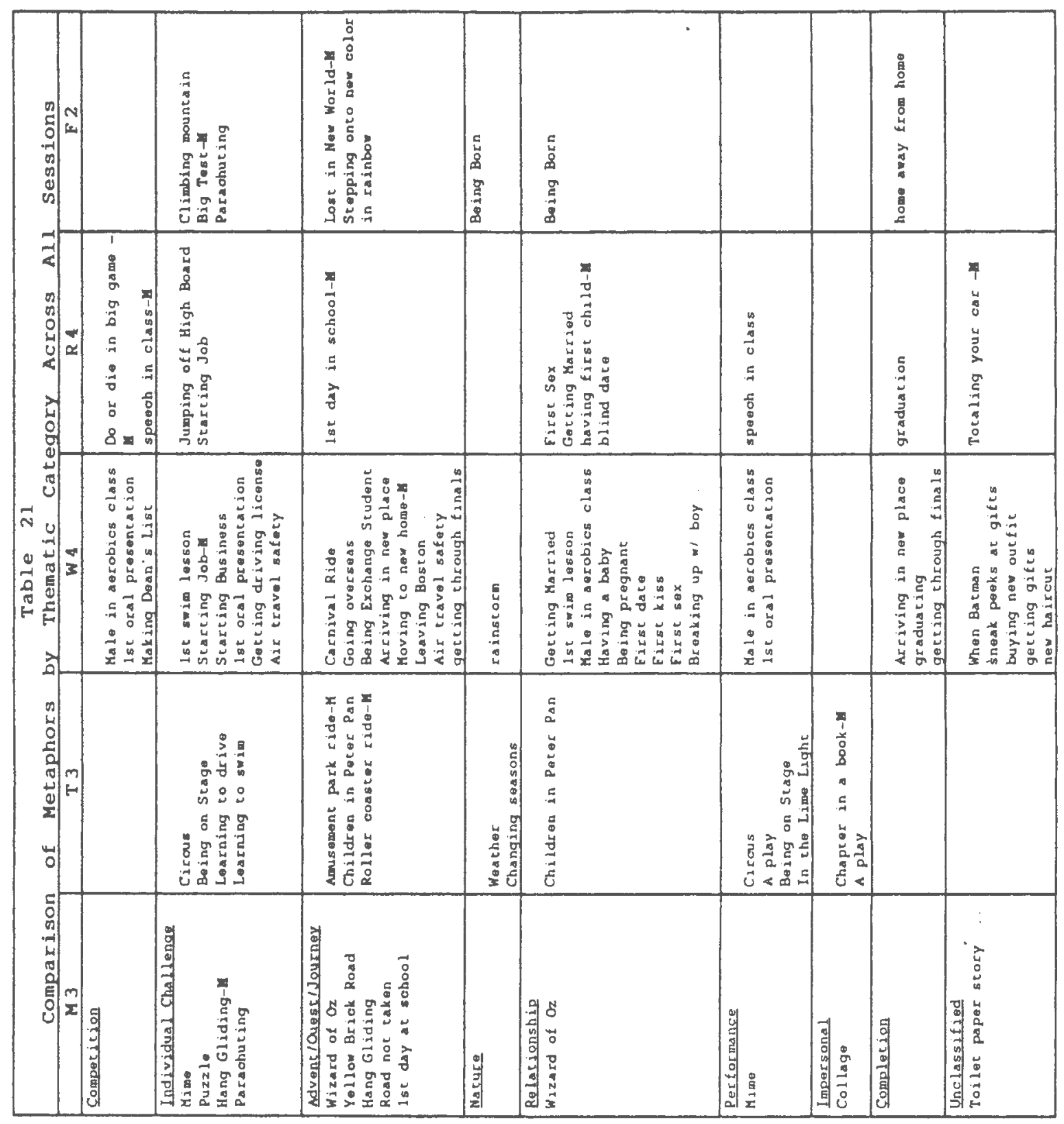


Miles and Huberman observe that the wider the difference between the denotative and connotative meanings in a metaphor, the greater its creative potential. In Gordon's synectics, this notion has to do with the the difference between 'decorative' and 'generative' metaphors.

Pollio (1977) cites I. A. Richard's and Osborn and Ehninger's notions of the relative gap between the 'vehicle' and 'tenor' in a metaphor. Tenor is understood to be the subject of the metaphor and vehicle the item for association. Pollio uses for an example the following:

in the phrase ... "The British Constitution is our foundation", "British Constitution" is the subject and "foundation" is the item for association. ( $p$. 42,1977 )

Analogously, therefore, "Beginning College" as represented by the Meaning contained in the Consensus Cluster is the Subject of Metaphor Making in Phase 1. The Item for Association is the Denotative Meaning of each group's Consensus Metaphor.

The relative 'height' of the tenor/vehicle gap suggests for Richard the difference between 'dead', 'established' and 'radical' metaphors. Pollio has adopted the terms 'frozen or cliched' and 'novel'. For the purposes of the present research, Pollio's terms will be used. The researcher chooses to interpret 'cliched' as also encompassing 'private' metaphors having connotative meaning to small in-groups. Within these in-groups, the private cliche is perfectly valid 
and perhaps quite evocative, but its vehicle/tenor gap does not have the potential for a significant degree of generalizability.

An initial effort to apply Pollio's typology to the Consensus Metaphors suggests that Hang Gliding and Weather may be considered 'novel' and Facing a Big Test, starting a New Job, and First Sex 'frozen or cliched'. Of the 14 remaining Principal Metaphors, the researcher considers eight to be Novel. It is of further interest to note that Pollio's (1977) criteria for inclusion of a Metaphor in the Novel category is total Consensus among three judges. Further implications of Pollio's typology for the present research will be discussed below in the Inside the Metaphor subheading.

Another focus of Metaphor analysis for the present research will be Thematic Categories of Metaphor. Given the hypothesizied Phase 2 application of Seed Metaphors, both the creative or evocative potential (novelty) of a Metaphor and its Thematic character as a building block for Mythically framed life story must be considered. Many categories suggest themselves. The contemporary discussion in the Profession regarding gender differences in the developmental paths which undergraduates appear to follow presented a starting point for the categories shown in rows $A$ through $F$ in Table 20. (Gilligan, 1982, Marcia, 1970, 1976, 1980)

The initial categories chosen were Metaphors of Competition; Individual Challenge; Adventure, Quest \& 
Journey; Nature; Relationship; and Impersonal. When analysis identified more than one thematic category, the Metaphor was included in both. Beginning with the Consensus Metaphors, Table 20 indicates that Metaphors in Row B, Individual Challenge, were chosen in three of five cases. It is of further interest to note that these are the identical Consensus Metaphors which were suggested by Males and discussed above with regard to the possibility, of a Gender, Diversity or Minority effect. This observation suggests that a relationship involving theme and gender may exist or that the relationship involves theme alone. In either case, it appears that a correlation within the Metaphor Making stage exists and is supported by the criteria of Credibility and Consistency espoused by Kuh et al. (1986)

Of further note along the same lines is the observation that of the nineteen Principal Metaphors listed in Table 20, 47.4\% fall into the Individual Challenge Category. The next most populated categories are Relationship (26.3\%) and Adventure/Quest/Journey (21.1\%) followed by Nature (10.5\%), Impersonal $(5.3 \%)$ and Competition (0.0\%).

When all Metaphors generated in all groups are analyzed (Table 21), the most populated categories are Individual Challenge (27.5\%), Adventure/Quest/Journey (27.5\%) and Relationship (23.2\%). Table 22 indicates populations for each Category described in Tables 20 and 21. 


\section{Table 22}

Percent of Metaphors in Thematic Categories

Thematic Category

Competition

Individual Challenge

\% Principal

\% All

Metaphors

Metaphors

Adventure/Quest/Journey

Nature

47.4

7.3

Relationship

21.1

10.5

27.5

Performance

26.3

27.5

Impersonal

5.3

5.8

Completion

23.2

Unclassified

12.6

4.3

7.2

10.1

Note. Adds to more than 100 due to assignment in more than one category.

\section{Inside the Metaphor}

Efforts to analyze the content of the Inside the

Metaphor steps across groups will be restricted since a

protocol for comparing language or themes has not yet been developed. It is the researcher's sense that compared with other Phase 1 steps the participants are more reflective and exhibit more critical thinking while Inside the Metaphor. If this observation is true, it would be appropriate to ask whether there is a sensitizing effect from the earlier steps of the process. It would also be appropriate to ask if this result was due to the creative effect of the Metaphor alone.

Pollio's taxonomy involving Novel and Frozen metaphors may be helpful in more rigorous future examinations of the content of this step in Phase 1. The present research makes a tentative effort in this direction.

An assignment of Novel was made to M3's Consensus Metaphor 'Hang Gliding'. Table 23 indicates that the language used Inside this Metaphor is general (accomplishment, satisfaction, challenge, exhilarating, 
careless); introspective/reflective (peak experience, inner peace, seeing ...with different perspective, timeless, existential experience) and consequential/critical (something could break, risky, rise/fall with ..., dependent ..., reliance on others ...risk vs. reward, limited control). Though perhaps premature, it is interesting to note that concepts related to spirituality such as timeless, existential experience, peak experiences and inner peace seem present in this M3 content.

Pollio's Novel label has also been assigned to T3's Consensus Metaphor, the 'Weather'. In this case, significantly general notions such as (constantly changing, laughter, joy, unpredictable) are also present. Reflection seems to be present in ideas such as (cycles, season to season, gives life, takes ...gives back, ...perspective). Perhaps due to the clearly external locus of Weather, there seems less introspection, though the quality of reflections such as that dealing with life, death and rebirth is quite impressive. The maturity of this observation coupled with the consequential/critical thoughts such as (control ... through preparation) may be related to the greater number of Juniors and Seniors in the group. Once again, though premature, the spiritual shading of some of this group's content is worth noting. 


\begin{tabular}{|c|c|c|}
\hline $\begin{array}{l}02 \\
5 \\
0 \\
-1 \\
0 \\
0 \\
0\end{array}$ & 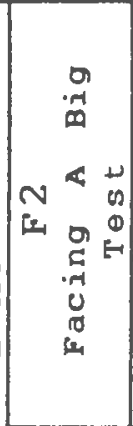 & 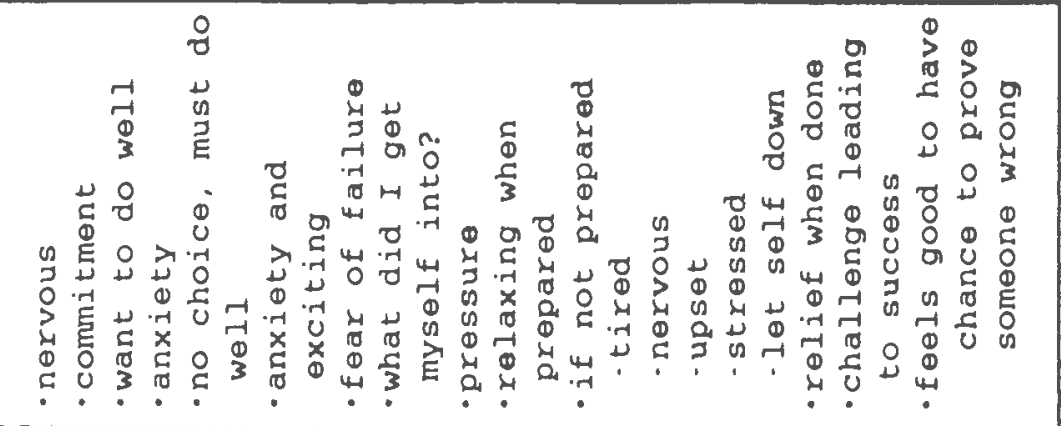 \\
\hline $\begin{array}{l}0 \\
0 \\
0 \\
4 \\
0 \\
0\end{array}$ & 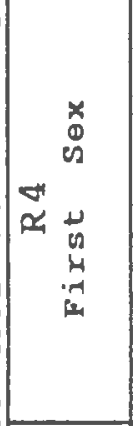 & 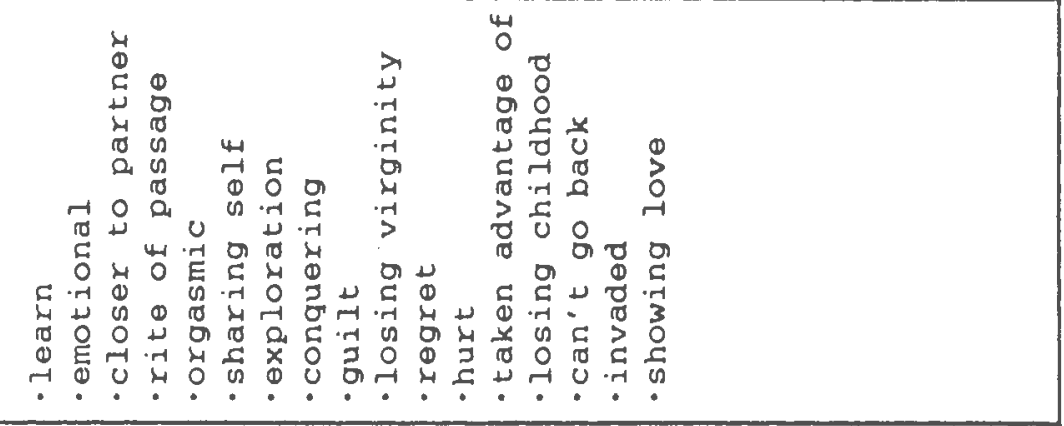 \\
\hline 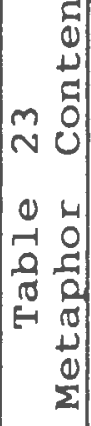 & 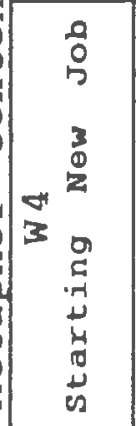 & 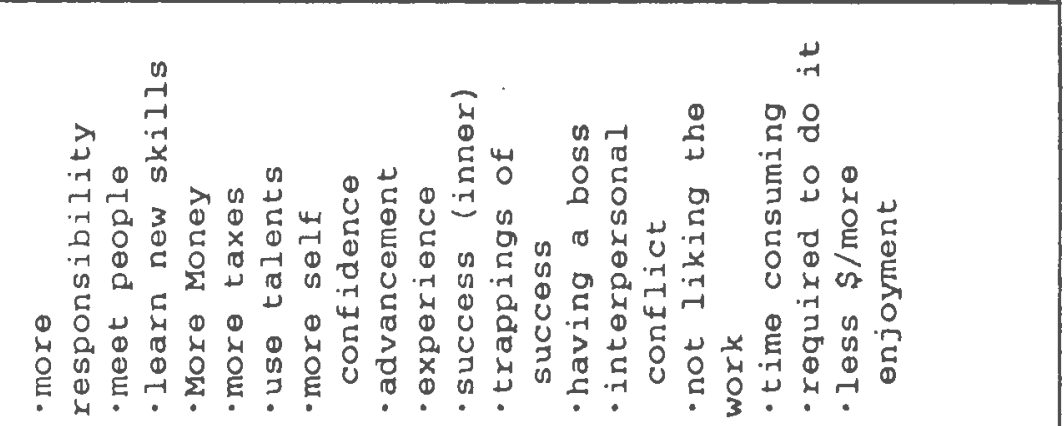 \\
\hline 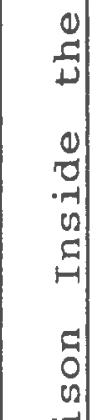 & 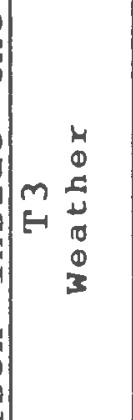 & 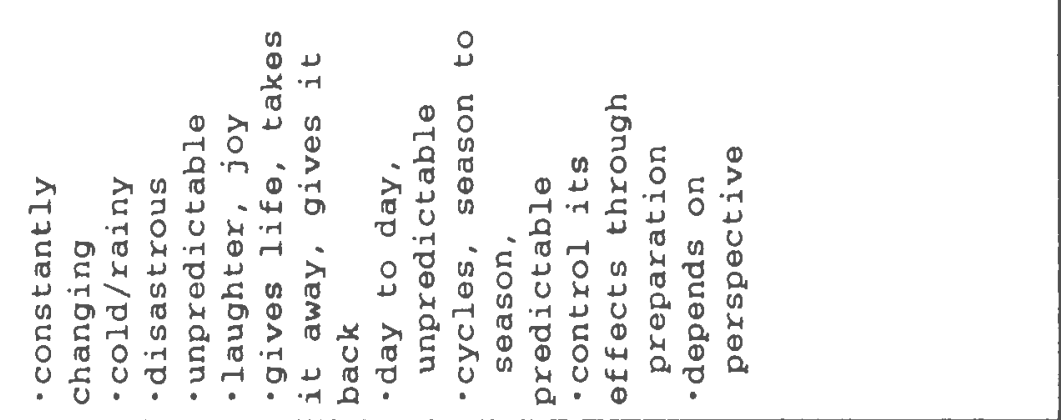 \\
\hline $\begin{array}{l}\text { a } \\
0 \\
0 \\
0 \\
0 \\
0\end{array}$ & 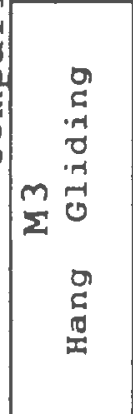 & 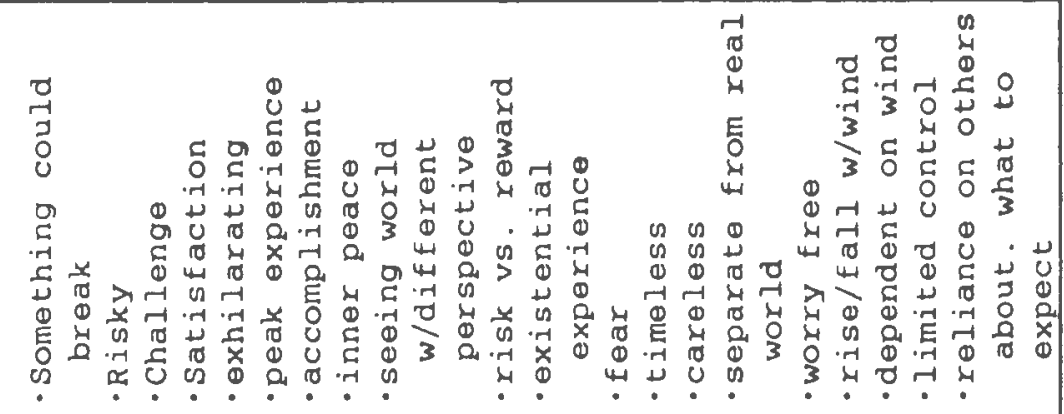 \\
\hline
\end{tabular}


The Frozen label on W4's 'Starting a New Job' metaphor appears appropriate. For the most part, each of the words chosen are specifically applied to the career setting participants would likely have been imaging. This is not necessarily negative in terms of areas such as consequential/critical since developing this discipline is an age appropriate activity. It is clear that there is a closed or frozen loop between beginning college and starting a new job. It is also true, that the content of the Inside the Metaphor step indicates considerably more reflection than the Thoughts/Feelings step. The locus of interest is fairly self centered (success, money, use talents, advancement, time consuming), though several relationship ideas surface (having a boss, interpersonal conflict, meet people). It is also to be observed that W4's fairly self centered reflection occasionally did yield less materially oriented ideas (inner success, less \$-more enjoyment, and more responsibility) as well.

The Frozen label for R4's Consensus Metaphor, 'First Sex' may seem misleading. Certainly, the content from within this metaphor generated mature reflection (learn, rite of passage, emotional, exploration). Consequential/critical (guilt, conquering, losing virginity, regret, losing childhood) and relationship (closer to partner, showing love, hurt, sharing self) also characterized the insights from within this Metaphor. Beyond the idea of a rite of passage, 
it is, however, difficult to identify a sense of the general in this Metaphor.

With regard to spirituality, it is especially interesting to consider R4's 'First Sex' metaphor in the light of Keutzer's (1978) study. Keutzer compared student responses to a list of triggers to transcendent experiences enumerated in a survey of adults conducted by Greeley in 1974. Keutzer observed that while 18\% of Greeley's adults considered "sexual lovemaking" such a trigger, $14 \%$ of the students agreed. Among the other major triggers for students were Beauties of Nature (45\%); Moments of Quiet Reflection (42\%); Listening to Music (32\%); Drugs (22\%); Physical Exercise (21\%); Watching Little Children (19\%) and Reading a Poem or Novel and [Doing] Own Creative Work (18\% each). In this group of 146 Juniors and Seniors, Prayer was a trigger for $16 \%$. As compared to about two in every three adults studied by Greeley, one in three students reported having an experience at least once in which they "felt as though [they] were very close to a powerful, spiritual force ..." (1978, p. 77 )

The Consensus Metaphor derived in F2 is also considered Frozen. Of the three so labeled, this may be the least frozen. Much of the content is general (no choice, must do well, anxiety, fear of failure, nervous, commitment). Some degree of consequential (relaxing when prepared, challenge leading to success, relief when done) is also contained. Given, however, that there seems little in the critical or 
reflection area, it may be that as Miles and Huberman (1984) warn, moving prematurely to metaphor may restrict its data reduction and containing function. Once the participants were invited to return to the beginning college experience, (Appendix E, Thoughts/Feelings) the level of reflective content appeared to increase.

Within Groups: Content Review

Two idiosyncratic occurrences during session F2 are notable.

After the Guided Image, the researcher was engaged in a discussion with a minority student who indicated that he did not feel his initial college experience would fit the process. Currently a senior, he felt that because he had started in a program which included a tutoring component at the University's urban campus while he was till in High School, it would be difficult for him to relate to the process. Additionally, at the time he enrolled, the University's orientation program was different for this group of entrants and by the time the fall semester began, he had already been on campus for some six weeks during the summer.

The researcher's response was to encourage the participant to find his own place in the process and to be as active an observer as he might choose. Interestingly, this student became one of the more active participants. He subsequently contributed a Principal Metaphor and expressed four of the six thoughts and feelings from inside of the metaphor. A more rigorous examination of the other sessions 
which involved students from the same program may be appropriate.

Within the same group, F2, during the Metaphor step, the researcher observed a qualitative difference in the Metaphors contributed by a senior participant with a significant, though not visible, physical disability. The researcher had recently read a story in the campus newspaper about this female participant and her disability. This participant contributed the Metaphor relating to Stepping onto a Different Color on a Rainbow and to Climbing a Mountain. From the standpoint of assessing spirituality, it should be noted that both Rainbows and Mountains are significant and considered archetypal in many spiritual and religious traditions. 


\section{Summary, Conclusions, Recommendations}

\section{Summary}

Human Development in the college years is a time in which Life Story, has a direct, shaping function and meaning to Identity formation. To McAdams (1985) Life story is Identity. Embedded within an individual's story is the evolving and projected chronicle of relationship with self, other, nature and the Ultimate that may be understood as spirituality. To study spirituality is to respond to the Profession's call to attend to the whole individual. It is the present researcher's thesis that to study the whole person's story is to study the person's spirituality.

Intrinsic to this thesis is the awareness that persons across all cultures come to understand competence and goodness through the shaping effects of shared, culturally projected story during the years corresponding to Erikson's Stage IV. During Stage $V$ individuals are engaged in making these stories into their stories. During the College years, the Student Development Profession and the entire Higher Education Community have the opportunity to help these individuals write and rewrite harmonious, productive, and positively generative (Stage VII) future scripts.

Because these students have learned through image, metaphor and myth prior to adolescence (McAdams, 1985, Fowler,1981,1985) and because cognitive development constructs suggest they tend to be most expressive in imaging modes as adolescents and young adults (Fowler, 1981, 1985, 
Mosely et al. 1986) it is expected that metaphor and myth can play important data collection and analysis roles in studying Student Development.

A Methodolgy reflecting these perceptions was developed and Phase 1 of its implementation has been reported in the present research.

\section{Conclusions}

The following conclusions can be drawn from the research.

1.) Several groups of students can be guided to reflect on a common experience in such a way that the core cognition and affect (Consensus Cluster) involved in that experience can be extracted with what is understood to be high levels of the qualitative research analogs of internal validity (credibility) and reliability (consistency).

2.) The process can be extended to evoke, through reflection on the Content Cluster, verbal images (Metaphors) which contain the experiential meaning of the content Cluster.

3.) Some of the Metaphors generated (Consensus Metaphors) have the property of Novelty. This property appears to stimulate creative, reflective and more general ways of understanding and experiencing the meanings carried by the Metaphor. Some of these meanings derive from the original content cluster. Others may be information carried or created by the Metaphor itself or by the dynamic process 
which creates the Metaphor at the group participant's Heights and Depths of Consciousness (von Eckartsberg, 1981)

4.) The process itself seems to enable more reflective and more critical thought among participants.

5.) The process appears inclusive enough to incorporate several different ways of experiencing or points of view regarding a common experience. This accommodation of diversity apparently incorporates gender, transcends culture, and embraces different categories of students including transfers, commuters and the physically challenged.

6.) The use of Guided Image in a relatively nondirective way and the continued efforts of the facilitators to accept the language of the participants would seem to minimize the shaping of the Data by the Leaders. Essentially, the Participants are the Research instruments as regards Data Collection, Reduction and a good portion of Display. It is helpful to note that since this is the case, Phase 1 of the Methodology is self updating. That is, the language, images and modes of thought of the Participants at any time in the future would have internal validity or credibility (truth value) for that time, in that place with those particular Participants. The issue of whether the seed Metaphors drawn from these processes would have the self updating property is a matter left for future consideration. Recommendations

Recommendations growing out of the present research fall into three categories. 
1.) Adjustments to the Phase 1 Data Collection Process.

- Though Gordon (1961) recommends the serving or preparation of food as a team or community building vehicle, it may be argued that the flow of a Phase 1 session could be adversly affected by the interruptions at times. A test protocol which attempts to assess this element of the process would be useful.

- Neither the Phase 1 process nor Phase 2, involves the disclosure of direct, explicit personal information. It is expected that because participants are involved in sharing fragments of their experiential perceptions, the process is relatively safe from an emotional standpoint. However, as was the case in each session, it is recommended that all participants be made aware of how and where the facilitators and other institutional resources (eg. Counseling Center) can be reached if any matter concerning the process or their experience of it develops.

- For some groups, education as to what Metaphor is should be considered part of the protocol. For the purposes of stimulating creative activity, the present research was unable to identify any notable outcomes to various definitions or means of communicating the notion of Metaphor at the beginning of that step in the process.

- Though the present research is hopeful to assess Spiritual Development, the term 'student development and awareness' was used at all times to describe what the process involved. It was not until the SOI was actually distributed that the word spiritual appeared. It is the researcher's current conviction that contemporary usage of this term is often too vague and contains considerable 'semantic baggage' that might repress or distort the Metaphor generation process.

- As an effort to be conscious of 'where the 'researcher's feet are'10 as research into

10 The reader may refer to the Preface of this Thesis for the context of in which this Metaphoric usage was developed. 
Spiritual Development and Awareness proceeds, it is recommended that some quantitative measures be used. Both the MBTI and the SOI have provided the present research a reassuring Field and Fence within which to ground the ongoing development of process and theory. Much as light appears at once to possess the properties of discreet quanta and analog wave forms, the study of spirituality seems to require an ability to keep one foot in the finite and the other with the infinite. In the event time is limited, the uses of quantitative measures could be minimized in favor of allowing time for the Metaphor generation steps.

- Whenever disclosure and other participant privacy considerations allow, the protocol should enable the researcher to identify which Metaphors have been contributed by individual participants. This was possible in one session during the present research. In addition to the potential value in Research, this recommendation may have implications regarding Clinical Assessment as indicated below.

2.) Future Assessment and Research applying the Phase 1

Data Collection Methodology.

- An immediate and potentially revealing Pre/Post study involving the sensitizing effect of the HCF150 Personal Development course should be undertaken. This research would include a concurrent Pre/Post study of a similarly composed class involving participants who had not yet taken HCF150.

- A group of homogeneous, special populations should be assembled and The Phase 1 process administered. Among the populations which should participate are:

- alumni

-athletes

-class status groups, traditional aged

- commuters

- disabled students

- dropouts

- gender specific groups

- international students 
- judicial cases

- minorities

- non-traditional students

- sexual preference groups

- specific majors

- substance abusers

- the Greek community

- transfers

- undecideds

- Since, in some cases, these populations might be more comfortable with facilitators who are themselves representatives of the population, the present researcher suggests that a facilitator training workshop be developed incorporating the experience of a Phase 1 session.

\section{3.) Applications of Phase 1 Methodology as Clinical}

Assessment, Intervention and Curriculum.

- Significant potential for Clinical Assessment is Eoreseen as Phase 2 Methodology is developed and applied. The principal potential for Phase 1 in the Clinical Assessment area is seen in the ability of the facilitator to observe peer interaction (Behavior) and an entire range of Cognitive, Affective and Creative responses in a fairly short, relatively in vivo and in situ circumstance. Inappropriate or otherwise unexplainable behavior along with evaluation of the character and quality of verbalizations. and Metaphor, perhaps along the lines suggested by David Gordon (1988) could be revealing. An anecdote from session F2 may illustrate this point. In the Metaphor stage, a participant contributed the image 'Jumping out of a Plane'. After a considerable pause, the Eacilitator asked 'Is that all?' More pause and then the facilitator said, 'at the risk of sounding parental, were you planning to use a parachute?'. Given that this participant's para and non verbals were reassuring, the facilitator chose not to pursue the discussion furthur. Applications of a specifically Clinical Assessment nature may include demographically identified or self disclosed at risk groups such as Career Change adults, children of divorce, individuals 
undergoing divorce, persons experiencing recent deaths among family, single parents, Codependents and Judicial Cases.

- An example of an Intervention application for Phase 1 involves the preparation of Learning Disabled or Physically Challenged students for developing Notetaking resources. It is expected that the development of Metaphors for the experience of asking for notetaking help from faculty and classmates as well as the experience of communicating about the associated issues will act as an agent of change.

- Among the potential applications as curriculum are those suggested by Phase 1's apparent capacity to accommodate diversity. This characteristic may be helpful in teaching students and staff about diversity issues. Whether metaphors are generated by a diverse or homogeneous group the capacity of the process to stimulate reflective and critical thought may provide a curricular effect.

- Finally, it is Phase 1's capacity to stimulate higher levels of reflection and critical thinking among traditional age college students that suggests its application as a means of stimulating developmental growth. Labeling this outcome as a result of an assessment, an intervention or a curriculuum may not be as important as noting that the application of such a process to Moral, Ethical, Psychosocial and other issues faced by college students today promises significant self teaching and self developing opportunities for participants. It seems reasonable to expect that

- commonly shared experiences as opposed to hypothetical dilemmas,

- contemporary language and images instead of instruments derived from studies of increasingly less representative populations

- and the synergy of creative, enabling and reinforcing peer/cohort support,

can contribute relevant, here and now awareness to all of the Higher Education Community. 
Appendix

\begin{tabular}{|c|c|c|c|c|c|c|}
\hline \multicolumn{7}{|c|}{ Appendix A: DaL Trom Session MB } \\
\hline & $\begin{array}{l}\text { Thoughts } \\
\text { Feelings }\end{array}$ & $\begin{array}{l}\text { Consensus } \\
\text { Cluster }\end{array}$ & Cons & $\begin{array}{l}\text { Metaphors } \\
\text { sensus Metaphor }\end{array}$ & & $\begin{array}{l}\text { Thoughts } \\
\text { Feelings } \\
\text { side Metaphor }\end{array}$ \\
\hline $\begin{array}{l}M \\
M \\
F \\
F \\
M \\
F \\
F \\
F \\
F \\
F \\
F \\
F \\
F \\
F \\
F \\
F \\
M \\
F \\
F \\
F \\
M\end{array}$ & 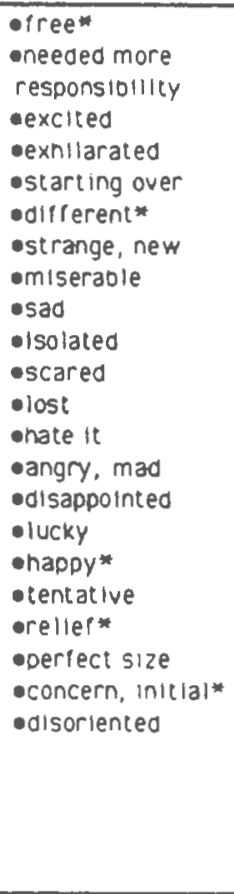 & $\begin{array}{l}\text { - free } \\
\text {-different } \\
\text { - hapoy } \\
\text {-relief } \\
\text {-concern, initial }\end{array}$ & $\begin{array}{l}F \\
F \\
F \\
F \\
F \\
F \\
F \\
M \\
F \\
F\end{array}$ & $\begin{array}{l}\text { - Wizard of Oz" } \\
\text {-yellow Brick Road } \\
\text { - Mime } \\
\text { - Road not Taken } \\
\text { - Collage* } \\
\text { - Tollet Paper Story } \\
\text { Exercise } \\
\text { - Puzzle } \\
\text { - Hang Gllaing* } \\
\text { - Parachuting } \\
\text { - Ist day at } \\
\text { Kindergarten } \\
\text { Jr Hign Scnool } \\
\text { Hign Scnool }\end{array}$ & $\begin{array}{l}M \\
F \\
F \\
M \\
F \\
F \\
F \\
F \\
F \\
F \\
F \\
F \\
F \\
F \\
F \\
F \\
F \\
M \\
M \\
F\end{array}$ & $\begin{array}{l}\text { - Something covid } \\
\text { oreak } \\
\text { - Risky } \\
\text { - Cnailenge } \\
\text { - Satisfaction } \\
\text {-exnllarating } \\
\text { - peak experience } \\
\text {-accomplishment } \\
\text { - inner peace } \\
\text { - seeling worid } \\
\text { w/dirferent } \\
\text { Derspective } \\
\text {-risk vs. reward } \\
\text {-existentlat } \\
\text { expertence } \\
\text { - fear } \\
\text { - timeless } \\
\text {-careless } \\
\text { - separate from } \\
\text { real world } \\
\text {-worry free } \\
\text { - rise/fall w/wind } \\
\text {-dependent on } \\
\text { wind } \\
\text { - Himited control } \\
\text {-rellance on } \\
\text { others about what } \\
\text { to expect }\end{array}$ \\
\hline $\begin{array}{l}F=1 \\
M=5\end{array}$ & $\begin{array}{l}7(77.2) \\
\quad(22.7) \\
\end{array}$ & $\begin{array}{l}F=3(60) \\
M=2(40)\end{array}$ & $\begin{array}{l}F=9 \\
M=1\end{array}$ & $\begin{array}{l}(90) \\
(10)\end{array}$ & $\begin{array}{l}F \\
M\end{array}$ & $\begin{array}{lll}15(78.9) & \\
4(21.1) & \mathrm{M3}\end{array}$ \\
\hline
\end{tabular}




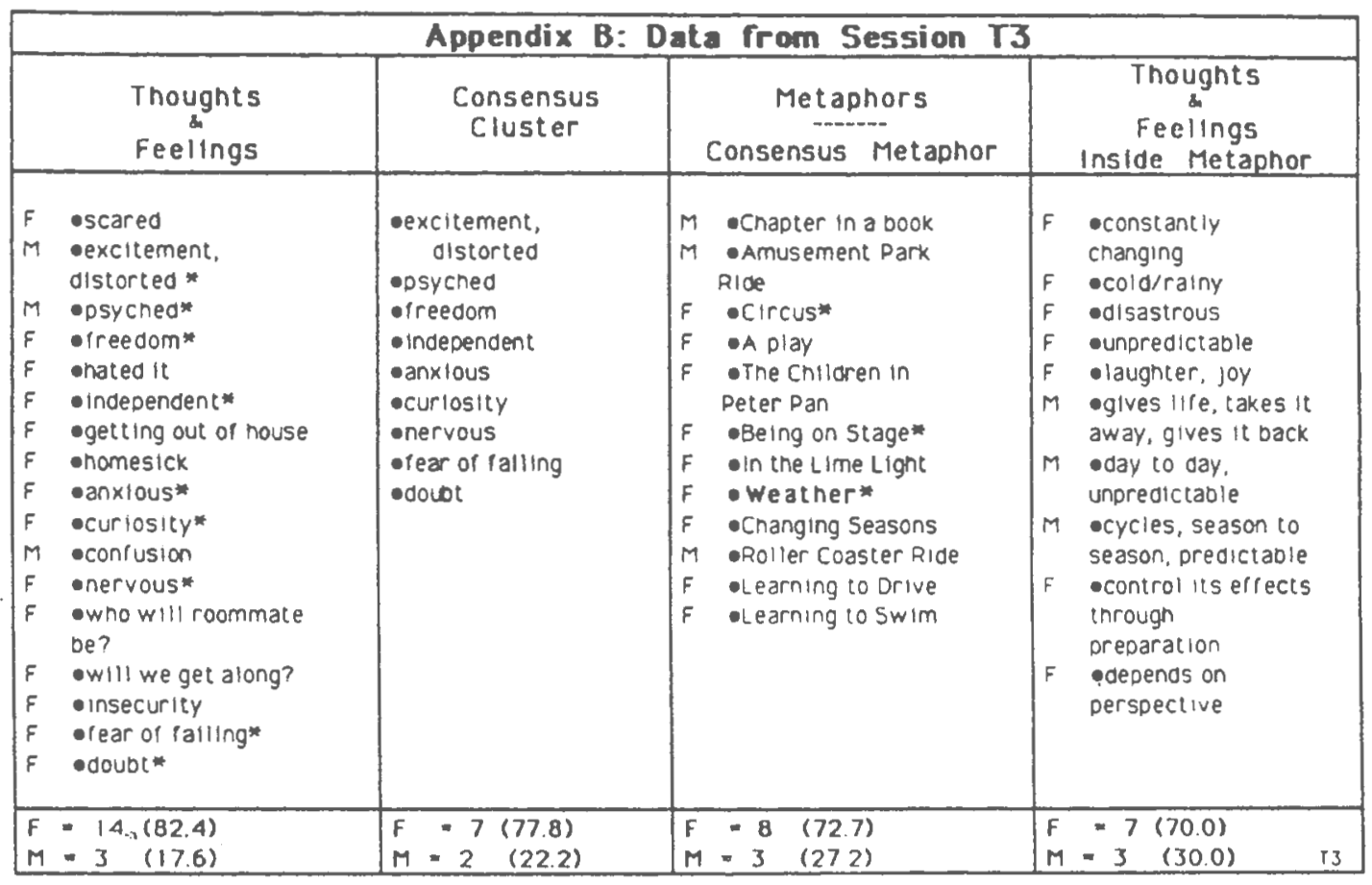




\section{Appendix C: Data from Session W4}

\begin{tabular}{|c|c|c|c|}
\hline $\begin{array}{l}\text { Thoughts } \\
\text { Feelings }\end{array}$ & $\begin{array}{l}\text { Consensus } \\
\text { Cluster }\end{array}$ & $\begin{array}{c}\text { Metaphors } \\
\text { Consensus Metaphor }\end{array}$ & $\begin{array}{c}\text { Thoughts } \\
\text { Feelings } \\
\text { Inslde Metaphor }\end{array}$ \\
\hline 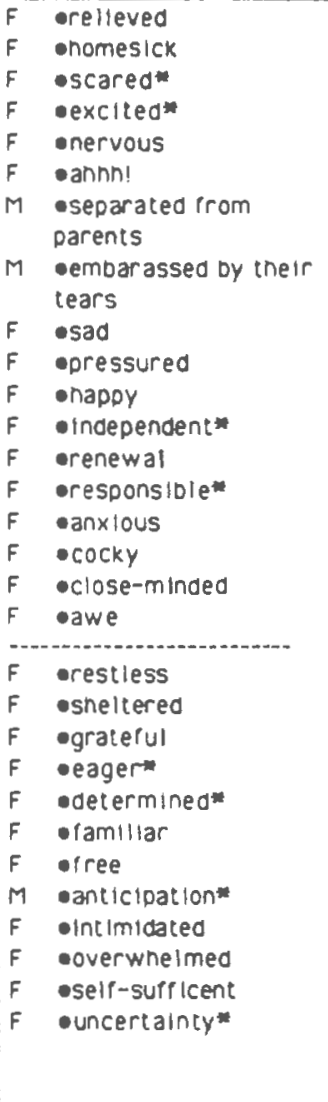 & $\begin{array}{l}\text { - scared } \\
\text {-excited } \\
\text { - independent } \\
\text { - responsible } \\
\text { - eager } \\
\text { - determined } \\
\text { - anticipation } \\
\text { - uncertainty }\end{array}$ & 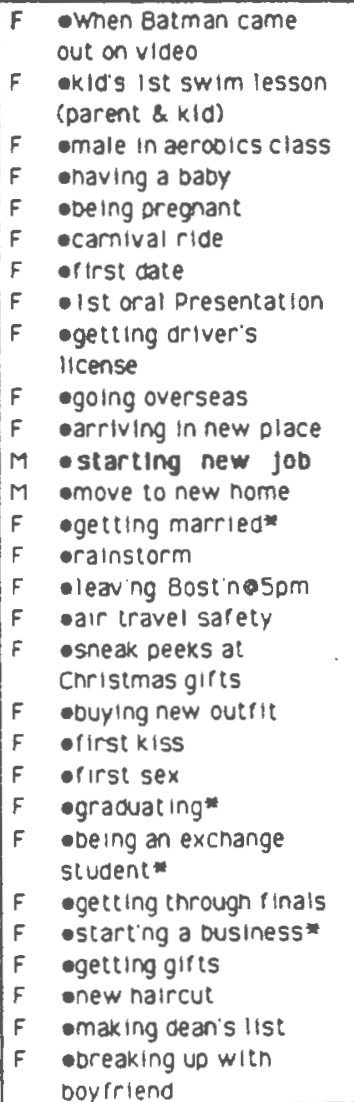 & 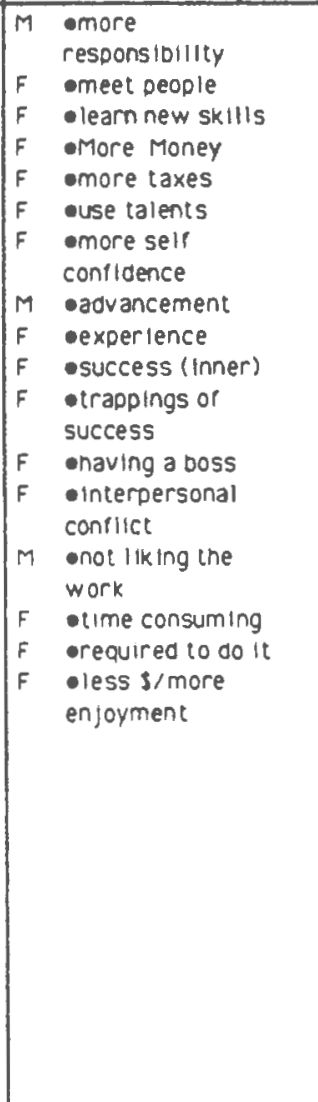 \\
\hline $\begin{array}{l}F=27(90.0) \\
M=3 \quad(10.0)\end{array}$ & $\begin{array}{l}F=7(87.5) \\
M=1 \quad(12.5)\end{array}$ & $\begin{array}{l}F=27(93.1) \\
M=2(14.5) \\
\end{array}$ & $\begin{array}{l}F=13(76.5) \\
M=4(23.6)\end{array}$ \\
\hline
\end{tabular}




\section{Appendix D: Data from Session R4}

\begin{tabular}{|c|c|c|c|}
\hline $\begin{array}{l}\text { Thoughts } \\
\text { Feelings }\end{array}$ & $\begin{array}{l}\text { Consensus } \\
\text { Cluster }\end{array}$ & $\begin{array}{c}\text { Metaphors } \\
\text { - Metaphor }\end{array}$ & $\begin{array}{c}\text { Thoughts } \\
\text { Feelings } \\
\text { Inside Metaphor }\end{array}$ \\
\hline 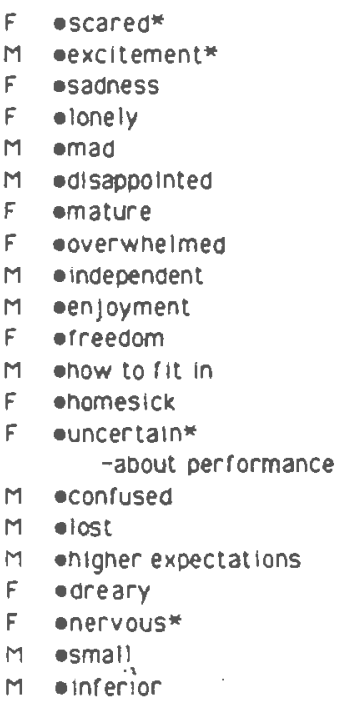 & $\begin{array}{l}\text { - scared } \\
\text {-excitement } \\
\text {-uncertain } \\
\text { - nervous }\end{array}$ & $\begin{array}{ll}F & \text {-ump off Hign board } \\
& \text { ior Ist time } \\
M & \text { - Totaling your car } \\
F & \text { - First Sex* } \\
M & \text {-0o or dle In big game } \\
F & \text {-getting married } \\
F & \text {-start new job } \\
M & \text {-having ist chlld } \\
M & \text { - Ist day Ist grade } \\
F & \text {-Hign School Grad'n } \\
F & \text { - Elind date } \\
M & \text { - Speech in class }\end{array}$ & 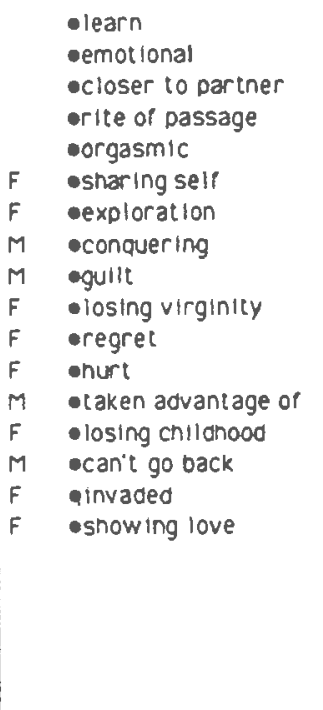 \\
\hline $\begin{array}{l}F=10(47.6) \\
M=11(52.4) \\
\end{array}$ & $\begin{array}{l}F=3(75.0) \\
M=1 \quad(25.0)\end{array}$ & $\begin{array}{l}F=6 \quad(54.5) \\
M=5 \quad(45.5)\end{array}$ & $\begin{array}{l}F=8(66.7) \\
M=4(33.3) \\
\end{array}$ \\
\hline
\end{tabular}




\begin{tabular}{|c|c|c|c|c|}
\hline \multicolumn{5}{|c|}{ Appendix E: Data from Session F2 } \\
\hline & $\begin{array}{l}\text { Thoughts } \\
\text { Feelings } \\
\end{array}$ & $\begin{array}{c}\text { Consensus } \\
\text { Cluster }\end{array}$ & $\begin{array}{c}\text { Metaphors } \\
\text { Consensus Metaphor }\end{array}$ & $\begin{array}{c}\text { Thoughts } \\
\text { Feelings } \\
\text { Inside Metaphor }\end{array}$ \\
\hline $\begin{array}{l}M \\
F \\
F\end{array}$ & $\begin{array}{l}\text {-overwhelmed } \\
\text { - independence } \\
\text { - fear of indep'dince } \\
\text { - what did I forget? } \\
\text {-never really prepared } \\
\text { If Test is Falled } \\
\text { - Orop course } \\
\text { - Find a detter ilt to need } \\
\text { - Increase } \\
\text { motivation/study } \\
\text { - Find different test } \\
\text { - Discouragement } \\
\text { - Retnini plans \& major }\end{array}$ & $\begin{array}{l}\text {-crazy place } \\
\text { - lonely } \\
\text { - scary } \\
\text {-exciting } \\
\text { - no nelp } \\
\text { - secure } \\
\text {-apprenensive }\end{array}$ & 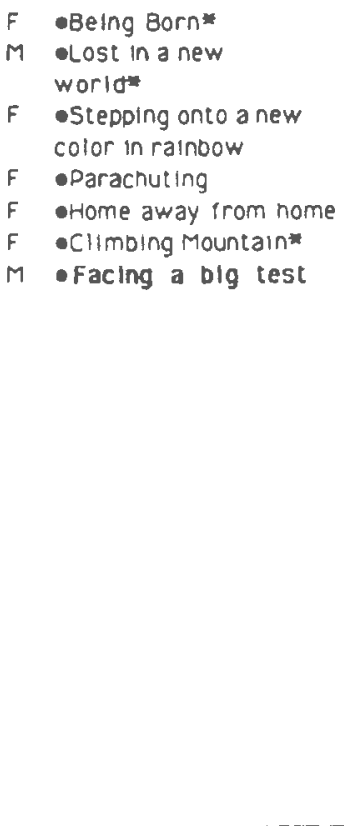 & 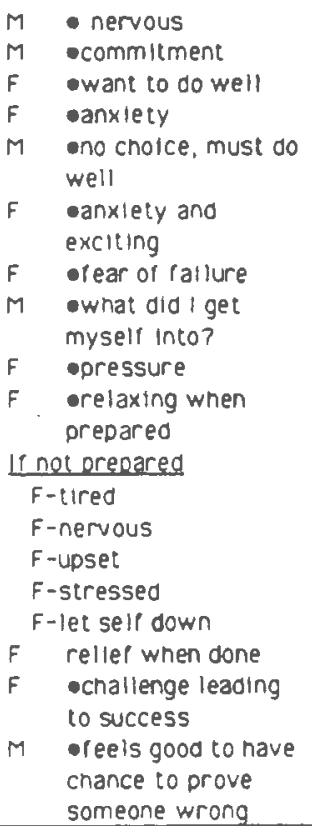 \\
\hline & & $\begin{array}{l}F=4(57.1) \\
M=3(42.9)\end{array}$ & $\begin{array}{l}F=5(71.4) \\
M=2(28.6)\end{array}$ & $\begin{array}{l}F=12(66.7) \\
M=6(33.3)\end{array}$ \\
\hline
\end{tabular}




\section{Bibliography}

Archer, J, Probert, B, Gage, L., (1987) College Students' Attitudes Toward Wellness, Journal of College Student Personnel 28(4) $311-17$.

Brewer, R. E. \& de Beer, J. (1986) Letting the Sources Flow In Brewer, R. E. Common Lessons: Series C Learning Resource Guide (pp. 9-17). The School of Theology, The University of the South: Sewanee, TN.

Butts, R. F. (1939) The College Charts its course NY:McGraw $\mathrm{Hill}$

Campbell, J. (1968) The Hero with a thousand faces 2nd Edition NY: Pantheon Books.

Campbell, J. (1972). Myths to Live By. NY: Bantam

Campbel1, J. and Moyers, B. (1988). The Power of Myth NY: Doubleday

Canda, E. R., (1986) A conceptualization of spirituality for social work: Its issues and implications. (Doctoral Dissertation, The Ohio State University.) Dissertation Abstracts Internationa1, 46, $2737 \mathrm{~A}$

Clapp, M. ed. (1950) The Modern University Ithaca, NY: Cornell University Press.

Collins, J. R. , Hurst, J.C. \& Jacobson, J. K. (1987). The Blind Spot Extended: Spirituality. Journal of College Student Personnel, 28 (3) $274-76$.

Conn, W. J. (1989). Spirituality and Personal Maturity. NJ: Paulist Press.

Cottrell, J. (1983, April) Guided Imagery as a Bi-Modal Approach to Preparation for Performance. Paper presented at the Annual Meeting of the Central states Speech Association, Lincoln, NE.

Delworth, U., Hanson, G. R. and Associates. (1980) Student Services: A handbook for the profession. San Francisco: Jossey-Bass.

Doty, W. G. (1986) Mythography: The study of myths and rituals. AL: University of Alabama Press.

duBarry, E (1975) Education for Ministry: Book 1: The Beginning Sewanee, TN: The School of Theology, The University of the South. 
Eliade, M. (1957) Myths, Dreams and Mysteries. NY:Harper and Row.

Elkins, D. et al. (1988) Toward a Humanistic-Phenomenological Spirituality : Definition, Description, and Measurement. Journal of Humanistic Psychology, 28, 4 5-18

Feinstein, D. \& Krippner, S. (1988) Personal Mythology. Los Angeles: Jeremy P. Tarcher, Inc.

Foshay, A. W. (1984, June) The Peak/Spiritual Experience as an Obiect of Curriculum Analysis. Paper presented at the Joint Meeting of the Social Science Education Consortium and the Bundeszentrale fur politische Bildung, Irsee, Bavaria, West Germany. (ERIC document reproduction service, ED 247 169)

Fowler J. (1981) Stages of Faith: The Psychology of Human Development and the ouest for Meaning. NY: Harper and Row.

Fowler, J. W. (1984) Becoming Adult, Becoming Christian $N Y$ : Harper and Row.

Gaylean, B. (1981) Guided Imagery in Education. Journal of Humanistic Psychology, 21, (4) 57-67.

Gilligan, C. (1982) In a different voice. Cambridge, MA: Harvard University Press.

Gordon, D. (1988) The Role of Language in Therapy. In J.K. Zeig \& S. R. Lankton, (Eds.) Developing Ericksonian Therapy: State of the Art, Proceedings of $3 r d$ International Congress on Ericksonian Approaches to Hypnosis \& Psychotherapy. NY:Brunner/Mazel.

Gordon, W. J. J. (1961) Synectics: The Development of Creative Capacity. New York: NY Harper \& Row

Hardcastle, B., Yamamoto, K., Parkay, F. \& Chan, J. (1985) Metaphorical views of school: A cross-cultural comparison of college students. Teaching \& Teacher Education. 1 (4), 309-315.

Hendlin, S. (1989) Evolving Spiritual Consciousness: Is "Religious Maturity" All There Is? The Counseling Psychologist, 17, (4), 617-619. 
Hettler, B. (1980) Wellness promotion on a university campus. Family and Community Health: Journal of Health promotion and Maintenance $\underline{3}, 77-95$.

Irving, C. (1989, August 27) Stanford alters Western history, culture program. The San Francisco Examiner pp. B1, B5.

Keen, S. (1988) The Stories we live by. Psychology Today. December . 43-47.

Kegan, R. (1982) The evolving self. Cambridge, MA:Harvard University Press: .

Keutzer, C. (1978) Whatever Turns You On: Triggers To Transcendent Experiences. Journal of Humanistic Psychology, 18, (3) 77-80.

King, P. M. (1978) William Perry's theory of intellectual and ethical development. Applying new developmental findings. New Directions for student services, \#4 (pp 35-51) Jossey-Bass:San Francisco

Knefelkamp, L., Parker, C.A. \& Widick, C. (1978). Jane Loevinger's milestones of development. Applying new developmental findings. New Directions for student Services, \#4 (pp 69-78) Jossey-Bass:San Francisco

Kuh, G., Shedd, J. \& Whitt, E. (1987) Student Affairs and Liberal Education: Unrecognized (and Unappreciated) Common Law Partners. Journal of College Student Personnel 28, (3) 252-260.

Kuh, G., Whitt, E. \& Shedd, J. $(1986,1987)$ Student Affairs Work 2001: A Paradigmatic Odyssey. Alexandria, VA: American College Personnel Association.

Lankton, C. \& Lankton, S. R. (1989) Tales of Enchantment: An Anthology of Goal Oriented Metaphors. NY:Brunner/Mazel

Lincoln, B. (1985) Discourse and the Construction of Society: Comparative Studies of Myth, Ritual and Classification. NY:Oxford University Press

Lincoln, Y \& Guba, E. (1985) Naturalistic Inquiry. Beverly Hills: Sage Publications.

Loomis, L. R. (Ed.) . (1942) Five Great Dialogues: Plato. Roslyn, NY:Walter J. Black, Inc. 
Marcia, J. E. (1966) Development and Validation of EgoIdentity status. Journal of Personality and Social Psychology $\underline{3} 5551-58$.

Marcia, J. E. (1967) Ego identity status: relationship to change in self-esteem, "general maladjustment," and authoritarianism. Journal of Personality, 35, 118-133.

Marcia, J. E. (1970) Ego Identity Status in College Women Journal of Personality 38 249-63.

Marcia, J. E. (1976) Identity Six Years After: A Follow-up Study, Journal of Youth and Adolescence 52 145-60.

Marcia, J. E. and Miller, E. C. (1980, April) Eqo Identity in Mature Women. Paper presented at the Annual Meeting of the Eastern Psychological Association. Hartford, CT.

McAdams; D. P. (1985) Power, intimacy and the life story. The Dorsey Press:Homewood Ill.

Miles, M. B. \& Huberman, A. M. (1984) Qualitative Data Analysis. Beverly Hills:Sage Publications.

Mills, J. \& Crowley, R. (1988) A Multidimensional Approach to the Utilization of Therapeutic Metaphors for Children and Adolescents. In J.K. Zeig \& S. R. Lankton, (Eds.) Developing Ericksonian Therapy: State of the Art, Proceedings of 3 rd International Congress on Ericksonian Approaches to Hyonosis \& Psychotherapy. NY: Brunner/Mazel.

Moseley, R. M., Jarvis, D. \& Fowler, J. W. (1986). Manual for faith development research. Atlanta: Emory University.

North-Shea, T. (1979) Cultural myth and personal metaphor: guided fantasy as therapy. Dissertation ABstracts International, 40, 3204-A.

Oswald, R. \& Leas, S. (1987) The Inviting Church: A Study of New Member Assimilation. Washington, DC: The Alban Institute.

Page, E. C. (1982) Finding Your Spiritual Path: An application of C. G. Jung's Theory of Psychological Types and the Myers-Brigas Tvpe Indicator. (Available from Center for Applications of Psychological Type, Inc., Box 13807, University Station, Gainesville, FL).

Paivio, A. (1971) Imagery and Verbal Process. NY: Holt, Reinhart \& Winston, Inc. 
Pollio, H. (1974) The Psvchology of Symbolic Activity.

Reading, MA: Addison-Wesley Publishing Company.

Pollio, H. R., Barlow, J. M., Fine, H. J. \& Pollio, M. R.

(1977) Psychology and the Poetics of Growth: Fiqurative

Lanquage in Psychology, Psychotherapy, and Education.

Hillsdale, NJ: Lawrence Erlbaum Associates.

Researcher reports professors take men more seriously. (1982,

April 11). The Providence Journal pp.1, A-9.

Rich, J.M. \& DeVitis, J.L. (1985) Theories of Moral Development. Springfield IL: Charles C. Thomas.

Roberts, K. (1984) Religion in sociological perspective. Homewood, IL: The Dorsey Press.

Roth, K. M. and McMahon, T. R. (1989, April) Visions of Koinonia: The Spiritual Development of College

Students. Paper Presented at the annual meeting of the American College Student Personnel Association, Washington, D. C.

Schafranske, E.P. \& Gorusuch, R. L. (1984). Factors Associated with the perception of spirituality in psychotherapy. The Journal of Transpersonal Psychology. 16, (2), 231-241.

Schiedel, D. G. \& Marcia, J. E. (1985) Ego Identity, Intimacy, Sex Role Orientation, and Gender. Developmental Psychology. 21 (1) 149-60.

Smith, A. F. (1978) Lawrence Kohlberg's cognitive stage theory of the development of moral judgment. Applying new developmental findings. New Directions for student Services,\#4 (pp 53 - 67) Jossey-Bass:San Francisco.

Von Eckartsberg, Rolf (1981) The Metaphors of Consciousness. In R. S. Valle \& Rolf Von Eckartsberg (Eds.), Maps of the Mind. NY: Plenum Press.

Widick, C., Parker, C. A. \& Knefelkamp, L. (1978) Erik Erikson and psychosocial development. Applying new developmental findings. New Directions for student Services, \#4 (pp 1-17) Jossey-Bass:San Francisco.

Wilber, K. (1979) A Developmental View of Consciousness. The Journal of Transpersonal Psychology 11, (1) 1-21. 
Wilber, K. (1987). The Spectrum Model. In Anthony, D., Ecker, B. \& Wilber, K. Spiritual Choices (pp. 237-264). Paragon House: New York.

Willis, G. \& Allen, A. J. (1976, April) Patterns of Phenomenological Response to Curricula: Implications. Paper presented to the annual meeting of the American Educational Research Association, San Francisco, CA.

Worthington, E. L. (1989) Religious Faith Across the

Lifespan: Implications for Counseling and Research. The Counseling Psychologist, 17, (4), 555-612. 